\title{
MODERNS AND ANCIENTS: THE “NEW CARDIOLOGY” IN BRITAIN 1880-1930
}

\author{
by
}

\author{
CHRISTOPHER LAWRENCE*
}

\begin{abstract}
In so far as there are two schools, an old and a new, in cardiology, there are two schools in the following sense. There is a small body of workers who spend their time and energies in the collection of new knowledge, a body of workers who insist upon proof to demonstration or an approach to that ideal. This school, if school it be, has been productive, some would say extremely productive, during the past few decades. There is, on the other hand, a large number of clinicians who speak and write largely upon questions of cardiac pathology, but who do not demand or seek exacting proofs, but are content, as far as these questions are concerned, with a more philosophic and therefore more indolent attitude. This school, if school it be, is sterile; it is sterile because of its method of thought and inquiry. ${ }^{1}$
\end{abstract}

\section{EXPERIMENTAL SCIENCE AND CLINICAL MEDICINE}

The debate as to exactly how the basic medical sciences have been used by clinicians to shape their practice is a long one. All too often, however, those who seek to show how a particular subject, such as experimental physiology, has been applied clinically point to a specific discovery, for example the isolation of insulin. Such a historical practice, though, misses the point. It perceives only the trees and not the wood. In this paper I shall explore how the work of experimental physiologists was used to reshape, fundamentally, clinical conceptions of the heart within British medicine during the first thirty years of this century. So aware were clinicians of the revolution that had taken place in perceptions of heart disease that they gave the subject which had been created a name, they called it the "new cardiology"."

The central argument in what follows is that crucial to the formation of this cardiology was the creation, by clinicians, of a new and highly specific concept: the "living heart". The clinicians who framed this concept drew on an account of the heart which had earlier been employed in the laboratory by English experimental physiologists. In this experimental account, the heart was characterized by the unique, living properties of its muscle; excitability, contractility, tonicity, conductivity, and rhythmicity. But although these properties were described as

\footnotetext{
*Christopher Lawrence, MB, ChB, MSc, PhD, Wellcome Institute for the History of Medicine, 183 Euston Road, London NW1 2BP

${ }^{1}$ Thomas Lewis, Lancet, 1917, i: 1012-1013.

${ }^{2}$ For an account of the debate on basic science and clinical medicine and some additional provocative thoughts, see Gerald L. Geison, 'Divided we stand: physiologists and clinicians in the American context', in Morris J. Vogel and Charles E. Rosenberg (editors), The therapeutic revolution, Philadelphia, University of Pennsylvania Press, 1979, pp. 67-90. In what follows, it is clear that I agree with Geison that in the instance of cardiology, physiology did not have obvious "utility" value. Its employment, however, profoundly changed clinical conceptions. I am unaware of the first use of the term "new cardiology", but it occurs frequently around the middle of the second decade of this century, sometimes as a term of abuse, see Sir John Parkinson, 'Leadership in cardiology', Lancet, 1955, i: 1013-1016. For contemporary usage see, for example, Lancet, 1917, i: 928 and passim.
} 


\section{Lawrence}

inherent in heart muscle, their day-to-day existence for physiologists was as laboratory artefacts produced by the use of the apparatus of modern physiology. The properties were handled as kymographic tracings or galvanometric deflections. The heart for working physiologists was constituted by laboratory methods. Instrumental examination of this sort was, of course, not feasible for clinicians interested in experimental science. The fundamental revolution engineered by the new cardiologists, therefore, was to redefine these properties in terms of the language of everyday clinical practice. Thus to various well-known symptoms and familiar clinical methods they gave new meanings. In addition, they used new techniques, such as polygraphic examination, in which the graphic results obtained were the indirect equivalent of those tracings produced by direct physiological interrogation. Thus the "living heart" was made by clinicians in the same way that, in the nineteenth century, other physiological properties, sensory and motor functions, had been used to define the nervous system. These latter properties made that system a unique, clinical object which could be studied by distinct techniques, for instance the use of a hammer to elicit a reflex, a response peculiar to the system itself. One feature common to all the properties ascribed to heart muscle was their temporal character. At the bedside, this meant that the clinical examination of the "living" heart became the scrutiny of ever-changing function. That cardiac disease was to be regarded solely as a change in function rather than in structure was, perhaps, how contemporaries most often defined the new cardiology. It was over this issue that most of the acrimonious debates occurred between the members of the old and the new school. The question of the relation between the new cardiology and the past is an important one, for it generated a distinctly Janus-faced rhetoric amongst the advocates of the new school. In defence of their account, they asserted the continuity of their studies with those of their predecessors. This was not surprising, since they self-admittedly held a view of medicine as a continuous tradition and they spoke of scientific knowledge as something that gradually accumulates. Yet, at the same time, they also asserted that they were saying something radically new about the heart and that earlier views were quite mistaken. This polarity followed from the fact that they were indeed giving quite new meanings to old terms, yet saw themselves as only adding to earlier knowledge.

The perceptual revolution entailed by the new account of the heart had other consequences, notably it made possible descriptions of new cardiac diseases. The intellectual transformation effected at this time was so thorough and longstanding that many of the clinical accounts of the heart disorders given by the new cardiologists remain similar to those in current use. We still use clinical terms such as atrial fibrillation and heart block virtually with their original meanings. However, the concern of the new cardiologists with the heart's dynamics also led to their interpreting well-known clinical events, notably angina and hypertension, in ways which are no longer accepted. This paper, incidentally, then deals with what seems to have been an intractable problem for "Whiggish" histories of cardiology; why in the face of "all the evidence" was the syndrome, later designated myocardial infarction, not described by such astute British clinicians as Thomas Lewis or James Mackenzie? I shall suggest that it could not have been described by the leading British thinkers 


\section{The "new cardiology" in Britain 1880-1930}

about the heart in the early years of this century because the "disease" was defined within an intellectual approach which they rejected. This paper, therefore, has as its more general theme the character of medical knowledge, how it is generated, and how it informs bedside perceptions.

What follows is in no sense meant to be a definitive account of early twentieth-century heart studies for, in some areas, it does no more than adumbrate an argument. It is intended as a heuristic model, an attempt to show how bedside practices were redefined to create a new account of the heart which was later institutionalized as a modern clinical discipline. Strategically, I will confine the argument almost entirely to diagnostic medicine, ignoring therapeutics and surgery. This is not to deny their later significance in clinical conceptions, but to indicate that, except for a new account of the action of digitalis, pharmacological and surgical considerations were not substantially embodied in the intellectual shape of the subject before the 1920 s. I shall suggest, in fact, that the new cardiology virtually precluded surgical therapy for heart disease.

The intellectual history of cardiology customarily begins with the mention of the heart in the Ebers papyrus. ${ }^{3}$ But cardiology in Britain means a specialized medical discipline, characterized intellectually by its orientation to a specific organ system, practised by consultants, usually in hospitals, who control within their gravitational field the minor planetary bodies of any specialized medical solar system; journals, symposia, specialist books, learned societies, funding mechanisms, and so on. The word cardiology itself was only coined in the nineteenth century and does not seem to have come into regular use until the second decade of this one. ${ }^{4}$ To begin the history of cardiology in Britain with the Ebers papyrus or William Harvey is to construct a respectable, positive lineage for a modern complex of medical ideas, practices, and institutions. More dangerously, such a history finds continuities where contemporaries perceived important disjunctions. To question the extended history of ideas approach is not intended to deny an importance to the Egyptian text on the pulse or to Harvey's account of the circulation of the blood. Rather, it is to state that the recovery of the meaning of these accounts for their contemporaries and the investigation of how such texts have been selectively used and given different meanings in later times seems to me a more appropriate task for the historian than intellectual genealogy. ${ }^{5} \mathrm{I}$ shall use as a working landmark for the intellectual establishment of the new cardiology in Britain the date 22 April 1922. On this day in Oxford, a Cardiac Club was formed. Its members comprised fifteen of the more distinguished physicians in Britain, with an additional honorary member, Sir James

\footnotetext{
${ }^{3}$ See, for example, James B. Herrick, A short history of cardiology, Springfield, Ill., Charles C Thomas, 1962 , p.6.

"The OED cities the earliest use as 1847 . It does not recognize "cardiologist", only the obsolete seventeenth-century term"cardiognost". The first supplement (A-G) cites the Lancet, 1885, ii: 576, as an early use of the term, referring to an unnamed physician as "a great cardiologist".

${ }^{5}$ There are several good histories of cardiology conceived as a discipline coeval with thought itself. A useful survey of these is by W. Bruce Fye, 'History of cardiology', in John A. Callahan, Thomas E. Keys, and Jack D. Key (editors), Classics of cardiology, Malabar, Fla., Robert E. Krieger, 1983, vol.3, pp. 614-616. For primary sources, an invaluable bibliography is L.M. Payne, The Evan Bedford Library of Cardiology, London, Royal College of Physicians, 1977. The formal structure of such anthologies and bibliographies, of course, implies conceptual continuity in the ideas which describe a "thing" called heart.
} 


\section{Lawrence}

Mackenzie. ${ }^{6}$ Most of the men who formed this club will be identified as the creators of new clinical concepts of heart disease, as well as the founders of institutions in which these concepts were used. They were not cardiologists in the modern sense, but general physicians with a particular interest in, and a new account of, heart disease. It would be easy to identify this new account of heart disease with the use of new techniques such as the electrocardiograph but, in the main, it was built by restructuring an older system whose major components can be defined in terms of clinical concepts, professional attitudes, and medical institutions.

\section{THE NINETEENTH_CENTURY LEGACY}

\section{Concepts}

By the end of the nineteenth century, the aspiring student of heart disease in Britain had available to him a rich investigative and explanatory structure composed largely of physical diagnosis and pathological anatomy. It was in France, of course, at the Paris school, that clinicians had developed bedside techniques for localizing cardiac pathology. Jean Nicolas Corvisart, who publicized Leopold Auenbrugger's method of percussion, published on the diseases of the heart in 1806. Corvisart's text reported his clinical discoveries of morbid anatomical states of the cardiac muscle and valves. The stethoscope, invented by René Laënnec in 1816, was soon adopted as a tool which could, apparently, increase the physician's power to detect local cardiac pathology at the bedside. The use of the stethoscope drew most attention to the cardiac sounds, which were, later, causally associated with the action of the valves. ${ }^{7}$ An interest in valvular disease dominated much of British clinical medicine in the nineteenth century. But again, it was a Frenchman, Jean Baptiste Bouillaud, who in 1835 described what increasingly became a central object of clinical inquiry, the relationship between acute inflammatory rheumatism and endocarditis.

\footnotetext{
- John Cowan, 'Some notes on the Cardiac Club', Br. Heart J., 1939, i: 97-104. Maurice Campbell, 'The British Cardiac Society and the Cardiac Club: 1922-1961', ibid., 1962 24: 773-695. Creighton Bramwell, 'John Hay and the founders of the Cardiac Club', ibid., 1965, 27: 849-855. My analysis in this paper is specifically concerned with the British clinical context, but I am not claiming that a general functional account of heart disorders was a British conception. It had a much more active life on the continent before 1900. See Knud Faber, Nosography and internal medicine, New York, Paul B. Hoeber, 1923, esp pp. 128-138. Rather, I am concerned with the introduction of this functional view into British medicine, and its elaboration into a very specific intellectual form. In this regard, a figure such as Thomas Lauder Brunton seems exceptionally interesting. Brunton died in 1916, but his name rarely occurs in the literature of the new cardiology. Brunton, however, might be said to have been one of the most physiologically-minded of physicians of the late nineteenth century. It seems to me, at present at least, that Brunton's physiological views of heart disease depended on his continental training and were actually rather different from the views expressed within the new cardiology. Not the least evidence in favour of this suggestion is that Brunton famously suggested surgical therapy for mitral stenosis, a treatment that was laughable within the new cardiology. See Campbell, op. cit., note 139 below, and Lauder Brunton 'Preliminary note on the possibility of treating mitral stenosis by surgical methods', Lancet, 1902, i: 352.

'See Victor Almon McKusick, Cardiovascular sound in health and disease, Baltimore, Md., Williams \& Wilkins, 1958; and Kenneth D. Keele, 'The application of the physics of sound to 19th century cardiology: with particular reference to the part played by C.J.B. Williams and James Hope', Clio Med., 1973, 8: 191-221. I say that the stethoscope apparently increased cardiac localizing capability because later clinicians have seen cause to doubt this. See Humphry Davy Rolleston, Cardio-vascular diseases since Harvey's discovery, The Harveian oration, Cambridge University Press, 1928, p.76.
} 


\section{The "new cardiology" in Britain 1880-1930}

Interest in the morbid anatomy of the heart and its clinical manifestations can be said to form a continuous tradition in British medicine, beginning at the end of the eighteenth century with the investigations of John Hunter and his nephew Matthew Baillie. One of the indicators of the growing use of pathological anatomy in nineteenth-century practice is that, increasingly, physicians wrote books on the disorders of anatomically defined organs, including the heart. Among the many famous examples of these are the treatises of the English physician James Hope in 1831 , and the Irishman William Stokes in 1854. The anatomical basis of many of these works is suggested by the fact that the object to which they drew attention was not the heart alone, but usually the heart and an adjacent part, most often the thoracic aorta. ${ }^{8}$ The other feature that distinguishes texts of this sort is that they were essentially narratives of personal clinical experience, not comprehensive, authoritative texts. Stokes said that his book "seeks to embody the results of my clinical observations, continued almost unremittingly for upwards of a quarter of a century". 9 In a sense, works like this were idiosyncratic expressions of individual genius, the fruits of research, often showing disagreement with other authors and by no means standard texts embodying a consensus.

One of the first publications of a rather different sort was Byrom Bramwell's Diseases of the heart and thoracic aorta of 1884. Bramwell was a pathologist and clinician at Edinburgh. His text was meant to be, as he said, "a systematic account of the Diseases of the Heart", the distillation of his lectures in the medical school. ${ }^{10}$ It was thus intended as a comprehensive, non-controversial textbook on heart disease. Such works are important, for they indicate the formation of a consensus as to the objects of study and methods of practice in bedside medicine. Bramwell's account considered four types of heart disease, the first three of which were classified by their anatomical seats, the pericardium, the endocardium (principally the valves), and the myocardium. The fourth category included the cardiac neuroses and angina. The disorders in this group were not defined anatomically but were symptoms whose anatomical seat might vary from person to person, or which were "functional" in the sense of non-organic.

In 1892 , what was possibly the most widely used medical textbook of the early twentieth century was published, William Osler's The principles and practice of medicine. John Parkinson, later a cardiologist, was at the London Hospital in 1905, and remembered Osler's book as "the most popular".11 Osler, not surprisingly, perceived the heart with the eyes of a morbid anatomist and classified its diseases in a manner similar to that of Bramwell. Osler's description of diseases of the heart covered seventy-two pages and comprised six categories, the odd one out being neuroses of the heart, which covered ten pages and comprised palpitation, arrhythmia, tachycardia, bradycardia, and angina pectoris. With this exception,

\footnotetext{
${ }^{8}$ Of the twenty-two books listed in Payne, op. cit., note 5 above, which are comprehensive, nineteenth-century, British accounts of heart disease, sixteen have titles which incorporate adjacent organs, such as the aorta or lungs. All of the twentieth-century textbooks are on the heart alone, except Paul Wood's book, which incorporates a physiological concept in the title: the circulation.

${ }^{\circ}$ William Stokes, The diseases of the heart and the aorta, Dublin, Hodges \& and Smith, 1854, preface.

${ }^{10}$ Byrom Bramwell, Diseases of the heart and thoracic aorta, Edinburgh, Young J. Pentland, 1884, preface.

${ }^{11}$ Parkinson, op. cit., note 2 above, p. 1013.
} 


\section{Lawrence}

heart diseases for Osler were ultimately structural entities, each of which produced its characteristic natural history and physical signs. Of these structural entities, the most important were valvular disorders, which accounted for more than two-thirds of the chapter. ${ }^{12}$ Osler's description of valvular disease merits closer examination in order that the contrast with the conception of heart diseases twenty-five years later can be made clear. Osler gave an account of each valve, referring, in sequence, to stenosis, dilatation, or a combination of the two. It is notable that he began with the morbid anatomy, and followed this with a description of the physical signs to be found in the chest. Osler, in common with all physicians, regarded the heart muscle as having exceptional powers of "compensation", allowing it to overcome most valvular defects. As he put it:"So admirable is the adjusting power of the heart that, for example, an advancing stenosis of aortic or mitral orifice may for years be perfectly equalized by a progressive hypertrophy." 13 However, eventually in some patients the hypertrophied heart would not be up to the mechanical task and compensation would "break". The effect of this would depend on the valve concerned, how badly it was damaged, and the cardiac chamber in question. Thus, failure of the left auricle in mitral stenosis would result in back pressure in the pulmonary system and "rapid and irregular action of the heart, shortness of breath, cough, signs of pulmonary enlargment, and frequently haemoptysis". ${ }^{14}$ In aortic incompetency, on the other hand, decompensation was marked by "shortness of breath and oedema of the feet ... general dropsy is not uncommon."15

The constellation of perceptions that makes up Osler's account suggests the following summary. There were distinct heart diseases, and the defining and most important feature of the majority of these was a specific valvular lesion. These valvular lesions produced clinical disorders with natural histories and physical signs, and it was the job of the clinician to identify these entities and assess the degree of severity of the illness, mainly by estimating the degree of valvular damage. A heart compensating for valvular damage was still a source of concern. When decompensation did occur it did so, at first at least, by failure of the specific chamber involved, although other chambers might be secondarily affected. The symptoms of decompensation were products of the mechanical obstructive effects of the valve concerned and the inability of the chamber to move a sufficient quantity of blood. This resulted in back pressure in the pulmonary or systemic circulation and in failure of forward flow, as, for instance, in aortic stenosis. These concepts were regulative as well as descriptive of clinicians' perceptions, since they served to direct attention to the heart's physical characteristics, its sounds, size, and impulses. Palpation, percussion and auscultation of the chest, and the volume and strength of the pulse, rather than its rhythm, were the cornerstones of cardiac practice. These clinical skills could be learned only by experience, and it was to this that many English clinicians

\footnotetext{
12 I include hypertrophy and dilatation in this two-thirds, since they were regarded by Osler as pathological states which were almost invariably the consequence of valvular disease. See William Osler, The principles and practice of medicine, New York, D. Appleton, 1892, pp.592-662

${ }^{13}$ Ibid., p.630

14 Ibid., p.618

${ }^{15}$ Ibid., p.607
} 


\section{The "new cardiology" in Britain 1880-1930}

appealed when asserting their belief that clinical medicine was an art to which the basic sciences had little to offer.

The portrait of the late nineteenth-century clinical perceptions I have drawn was also the one painted by a new generation of clinicians who were striving to replace it as the basis of bedside practice. John Parkinson, one of these new men, remembered that, at this time, clinical practice was "mostly empirical" and that there were "two kinds of heart disease, valvular and non-valvular". ${ }^{16}$ Clifford Allbutt, whose System of medicine of 1898 enshrined a clinical medicine similar to Osler's, but who later became a critical champion of the "new cardiology", wrote of the old in 1912:"Our fathers ... provided with a collection of the blunter facts of morbid anatomy took the matter more easily ... when ... they were introduced to diseases of the valves of the organ, and to coarse lesions of its substance, their difficulties were almost solved. The patient is dead, here is the lesion which caused his death, what more does one want?"17 Allbutt himself had been attracted to medicine after reading an article on the heart valves. ${ }^{18}$ Such a view had not, of course, disappeared by the time he was writing. During the First World War, men with heart disease were divided by military doctors into only two categories - VDH and DAH (Valvular Disease of the Heart and Disordered Action of the Heart), that is, organic and functional disorders. ${ }^{19}$

\section{Attitudes-the general clinician}

Recent historical work has shown that, in the late nineteenth century, hospital physicians, especially in London, were an élite group. ${ }^{20}$ Their lives, including their medical lives, were often dominated by non-medical values. Appointments could depend on good breeding and a sound classical education. For many British physicians, medicine was not an applied science, still less a skill, it was both a science and an art and one which qualified its practitioners to be the most experienced reflectors on the human condition. W.H. Broadbent, himself no mean student of the heart, stated the case this way in 1892: "The very business of our lives is the solution of intellectual problems of the most interesting character. On the large scale we see the working out of general laws, and vindication of the moral principles of right and wrong, the slow working of God's Will which grinds exceeding small.,"21

This attitude had particular consequences. First, it valued as the most important form of knowledge the accumulation of what was considered incommunicable, personal experience. Henry Pye-Smith, consulting physician at Guy's Hospital, wrote in 1900: "We must never allow theories, or even what appear to be logical deductions, or explanations however ingenious, or statistics however apparently

\footnotetext{
${ }^{16}$ Parkinson, op. cit., note 2 above, p.1013.

${ }^{17} \mathrm{~T}$. Clifford Allbutt, 'The physician and the pathologist on heart failure', Br. med. J., 1912, i: 653

${ }^{18}$ Humphry Davy Rolleston, The Right Honourable Sir Clifford Allbutt K.C.B., London, Macmillan, 1929 , p.60.

${ }^{19} \mathrm{See}$, for instance, Parkinson op. cit., note 2 above. The literature of the new cardiology is full of perjorative references to this classification.

${ }^{20} \mathrm{M}$. Jeanne Peterson, The medical profession in mid-Victorian London, Berkeley, University of California Press, 1978.

${ }^{21} \mathrm{~W}$. H. Broadbent, 'The intellectual interest of the study and practice of medicine', Br. med. J., 1892, ii: 778
} 


\section{Lawrence}

conclusive, or authority however venerable, to take the place of the one touchstone of practical medicine, experience."22

In this world of personal practical experience, anatomy and physiology were taught in the hospitals only in so far as they could be directly applied to clinical medicine. ${ }^{23}$ Such an anatomy and a "practical" physiology were, of course, the backbone of the diagnostic cardiology I have described. Many of the clinicians who practised this medicine viewed with suspicion the new experimental scientists who claimed that their disciplines were relevant to the clinician. Vivian Poore, Thomas Lewis's teacher at University College, addressing the students in 1900, noted: "You may be disappointed in finding that no inconsiderable part of the knowledge you have hitherto acquired is of little practical use to you in the wards." 24 The eccentric and much admired clinician Robert Hutchison was heard to remark: " . . . from too much zeal for the new, and contempt for what is old, from putting knowledge before wisdom, science before art . . . Good Lord, deliver us."25 Sir John Parkinson recalled that when he was a student "research in the wards had no place". ${ }^{26}$

The other accompaniment of this clinical attitude in English physicians was the higher valuation of generalism over specialism, for the latter implied narrowness of vision. It was probably the Fellows of the Royal College of Physicians who most discouraged specialization. They had good reason to do so, since, for much of the nineteenth century, specialists often meant either quacks or unlicensed practitioners. ${ }^{27}$ Surgery had been fragmented early on, and had recognized specialists in otorhinolaryngology, ophthalmic surgery, and, later, anaesthesia, but within general medicine things were rather different. Paediatrics and dermatology were soon regarded as relatively legitimate specialized offspring, and psychiatry had never really been within the respectable fold, but, otherwise, internal medicine was held to be homogeneous. "I remember well the time", wrote Sir John Parkinson, "when medicine was held to be indivisible . . . the word cardiologist was not in use or it was used unkindly.",28

Parkinson's recollection was not entirely accurate, for neurologists were clearly a distinct group. Of the fourteen societies which combined to form the Royal Society of Medicine in 1905 , bedside medicine was represented by two dermatological

${ }^{22}$ Phillip Henry Pye-Smith, 'Medicine as a science and medicine as an art', Lancet, 1900, ii: 309.

${ }^{23}$ See Gerald L. Geison, Michael Foster and the Cambridge School of Physiology, Princeton University Press, 1978, pp.13-48. Although by 1900 experimental disciplines were taught with varying thoroughness at the pre-clinical level, there is plenty of evidence that practising physicians did not regard them as clinically relevent.

24 George Vivian Poore, 'Science and practice', Br. med. J., 1900, ii: 984.

${ }^{25}$ Parkinson, op. cit., note 2 above. Hutchison, it should be noted, had worked in the physiology department of the London Hospital, R.R. Trail (editor), Munk's Roll. Lives of the Fellows of the Royal College of Physicians of London, vol 5: continued to 1965, London, Royal College of Physicians, 1968, p.209.

${ }^{26}$ Parkinson, op. cit., note 2 above. I am aware that the reminiscences of Parkinson and the other cardiologists whom I cite as evidence for the "style" of British medicine before the Great War have to be treated with care. They had an interest in representing themselves as the creators of a new medicine.

${ }^{27}$ See Rosemary Stevens, Medical practice in modern England: the impact of specialization and state medicine, New Haven, Conn., Yale University Press, 1966.

${ }^{28}$ Parkinson, op. cit., note 2 above. 


\section{The "new cardiology" in Britain 1880-1930}

societies, a neurological society, and the Clinical Society of London. ${ }^{29}$ In the new society, there were to be separate clinical and neurological sections but not a cardiological one. Even so, neurologists regarded themselves first and foremost as general physicians. But neurology did have a standing which cardiology did not. William Osler, writing in 1911, visualized hospital units composed of major and minor specialized departments. He included neurology among the major clinics. Cardiology was not suggested, even in a minor role. ${ }^{30}$

Any subdivision within internal medicine was usually resisted by those at the top. In 1897, William Carter, Professor of Materia Medica at Liverpool, wrote specifically criticizing those specializing in heart complaints: "The assumption seems to be that by this minute sub-division of labour, between us, and bit by bit, we can get to the very heart of things and solve all mysteries of life and diseases." The specialist, he went on, "devotes his whole mind and thought to a small section ... of the body and can see nothing and think of nothing except in relation to it." Such medical monomania was contrary to a generalist culture. "Take the heart", he said, "I have in mind a refined scholarly sensitive man, who ... had been led to place himself under the care of an eminent authority who had a special system .... The disastrous result was what might have been anticipated by any man of common sense and broad general ideas of a nervous man's constitution."31

There were, of course, good practical reasons for specializing, notably financial. ${ }^{32}$ Often, though, physicians who aspired to the top of the medical hierarchy and found themselves taking too much interest in a particular disease dropped it like a hot brick. William Broadbent, who believed he had discovered a method of treating cancer by injecting acetic acid, gave it up when faced by the dread possibility of becoming a "cancer specialist". 33

Yet another feature of this generalism in English medicine, and the valuation of a clinical art above a possible clinical science, was a disparagement of technology. In part, this arose from the association of new technologies, such as the sphygmograph, with the experimental disciplines, and perhaps it also followed from the fact that physicians were gentlemen and considered themselves a cut above surgeons who handled instruments. ${ }^{34}$ English physicians felt themselves well equipped without diagnostic aids, and indeed admired clinicians who did not need to touch the patient.

${ }^{29}$ Maurice Davidson, The Royal Society of Medicine, London, Royal Society of Medicine, 1955, p.31.

${ }^{30}$ William Osler, 'The hospital unit in university work', Lancet, 1911, ii: 211-213.

${ }^{31}$ William Carter, 'Authority in and out of medicine', ibid., Lancet, 1897, ii: 897-902, my italics. Carter was not opposed to all forms of specialization, though he clearly thought an organ as limited as the heart too narrow a field for practice.

${ }^{32}$ In Canada, where things were similar, Osler intended to become an ophthalmologist to make money so that he could work in research. Harvey Cushing, The life of Sir William Osler, Oxford University Press, 1940 , p.91.

${ }^{33}$ M.E. Broadbent, The life of Sir William Broadbent, London, John Murray, 1909, p.95.

${ }^{34}$ For a general account of instrumentation in nineteenth-century medicine, see Stanley Joel Reiser, Medicine and the reign of technology, Cambridge University Press, 1978; and Audrey B. Davis, Medicine and its technology, Westport, Conn., Greenwood Press, 1981. For two short studies of the sphygmograph in British medicine, see Christopher Lawrence, 'Physiological apparatus in the Wellcome Museum.1. The Marey sphygmograph', Med. Hist., 1978, 22: 196-200; and idem, '2.The Dudgeon sphygmograph', ibid., 1979, 23: 96-107. 


\section{Lawrence}

The young Broadbent related: "The senior physician, as you know, is Alderson, F.R.S. of high standing in the College of Physicians, ... old A. is a very shrewd fellow; . . . and, so far as I can see, he generally knows as much about a case when he has stood at the foot of the bed for a minute, and touched a man's pulse, as some other physicians after twenty minutes' hitting and fumbling.",35

When, later, physicians with a special interest in heart disease and a new approach to bedside practice began to make their mark in English medicine, they had either to accommodate themselves to or confront these various attitudes. For one thing, the new cardiologists proclaimed the relevance of experimental physiology. They were also using a number of new technologies, such as the X-ray, the polygraph, the electrocardiograph, the sphygmograph, and diagnostic serology, at a time when distrust of technology was still prevalent. Early in the twentieth century, many senior medical men continued to dislike instruments, and hospital governors would not subsidize specialized departments. Robert Marshall, appointed Resident Medical Officer at the National Hospital for Diseases of the Heart in 1913, remembered Sir Frederick Taylor, the consulting physician, expressing contempt for " $\mathrm{X}$-rays and the Wassermann reaction" in a case where the clinical evidence seemed transparent. ${ }^{36}$ Slightly earlier, in about 1908, John Parkinson at the London Hospital used the first sphygmomanometer possessed by the hospital. ${ }^{37}$ The instrument had been invented over thirty years before. When the first ECG machine was installed at St Bartholomew's Hospital, it was placed in the physiology department, so as not, it was said, to "offend too brusquely the susceptibilities of more conservative colleagues". ${ }^{38}$ Sir Ian Hill remembered that "Those who, like myself, experimented with this instrument were thought to be rather dangerous backroom boys, unfit to be trusted with the welfare of patients." 39 When Harold Cookson started as a house-physician at the Birmingham General Hospital in 1923, no one considered an ECG machine a suitable investment. ${ }^{40}$

\section{Institutions}

One possible reason why there were no cardiac physicians with a sense of group identity like that of the neurologists was because practitioners who might have pursued such interests had a different object of attention-the chest. Chest diseases were a well-recognized category in nineteenth-century medicine. The Brompton Hospital for Consumption was founded at the Manor House, Chelsea, in 1841, and,

\footnotetext{
${ }^{35}$ Broadbent, op. cit., note 33 above, p.46.

${ }^{36}$ Robert Marshall, 'Early days in Westmoreland Street', Br. Heart J., 1964, 26: 140-145. As instruments came into general use, the argument against them seems to have changed to challenging their use by students. In 1919, Allbutt reported: "Sometimes it is said to carry instruments of precision to the bedside blinds the student: that in fadding with instruments, even with the stethoscope, he forgets the use of his eyes." 'The new birth of medicine', ibid., 1919, i: 433-438.

${ }^{37}$ Parkinson, op. cit., note 2 above.

${ }^{38}$ Geoffrey Bourne, 'The birth of the cardiological department', St Bart's Hosp. J., 1959, 63: 38-40.

${ }^{39}$ Ian Hill, 'The wind of change in cardiology', Practitioner, 1968, 201: 44-45.

${ }^{40}$ Harold Cookson, 'Thirty years of cardiology', Br. med. J., 1957, i: 559-661. I have discussed the issues of clinical epistemology, specialization, and the use of technology during these years in 'Incommunicable knowledge: science, technology and the clinical art in British medicine 1850-1914', J. contemp. Hist., 1985, 20: 503-520.
} 


\section{The "new cardiology" in Britain 1880-1930}

in 1848, the London Hospital for Diseases of the Heart and Lungs was established. It was here that the chest physician, Thomas Bevill Peacock, studied the heart cases that were to comprise his 1858 text, On malformations of the human heart. ${ }^{41}$ Congenital anatomical abnormalities were, of course, an obvious object of attention for nineteenth-century physicians.

The idea of heart disease as an institutionalized object of study was not entirely alien to the Victorian medical mind. In 1857, the National Hospital for Diseases of the Heart was founded by a physician, Eldridge Spratt. One of the chroniclers of the hospital's past considered that its first years were more like melodrama than ordinary institutional history. ${ }^{42}$ Indeed, it must be one of the few instances where the founder of a hospital was disowned rather than honoured by the governors. Spratt seems to have brought this upon himself by liberally utilizing, for his own purposes, the hospital furniture, books, pictures, and collecting boxes. In 1874, the hospital was sited in a refurbished house in Soho Square. It had a few in-patients, but large out-patient facilities with, apparently, over 6,000 cases being seen in 1876 . During these years, the hospital was served by a number of consulting physicians. These men were not cardiologists even in the sense that other men were neurologists, they were general physicians who attended the hospital on a voluntary basis a few hours a week. Many of them had appointments at other general and special hospitals. All were of some standing in the profession, and most had published widely on a range of general issues and special subjects, notably ethnology and public health. Only two had published anything on heart disease. ${ }^{43}$ It is also noteworthy that in the years 1871-1901, of the first fourteen physicians to the hospital after Spratt, only one, Charles Aldis, was a Fellow of the Royal College of Physicians, and he had achieved that honour before he was appointed. The contrast with physicians practising neurology is quite striking. In the same period every physician appointed to the National Hospital, Queen Square, was or became an FRCP, and all of them researched or published extensively on neurological questions. The "National Heart", in other words, was an occasional site of practice for a few general physicians, near, but not at the peak of, the profession.

\footnotetext{
${ }^{41}$ It is less well known that Peacock also published accounts of dissecting aneurysm. See J.C. Leonard, 'Thomas Bevill Peacock and the early history of dissecting aneurysm', Br. med. J., 1979, ii: $260-62$.

${ }^{42}$ Robert Whitney, The place of hearts, 2 parts, London, [n.d.]; Maurice Campbell, 'The National Heart Hospital 1857-1957', Br. Heart J., 1958, 20: 137-139.

${ }^{43}$ George Hershell, appointed in 1893, published extensively on gastro-intestinal disorders. Kelly's London Medical Directory, 1896, credits him with a paper 'On the action of Convallaria majallis' (illustrated with sphygmograms)', Lancet, 1880, which I have been unable to trace. The Medical Directory, 1895, cites him as the author of 'Chest outlines for recording cases of heart disease' and 'A method of taking cases of heart disease', both dated 1894 , neither of which have I been able to trace. The same volume cites him as the author of 'On cycling as a cause of heart disease', Internat. Cong. Hyg., Budapest, 1894.

Charles Chapman, appointed in 1897, published Heart disease in childhood and youth, London, Medical Publishing Co., 1900 (2nd ed., 1903). Significantly, Chapman seems to have been out of a slightly different mould from that of his predecessors. His obituary states, "he gave all his thought and energy in arousing the hospital from the lethargy into which it had sunk since its foundation in 1857" (Lancet, 1941, i: 299). In 1927, he published, The heart and its diseases: a handbook for students and practitioners, Edinburgh, E. \& S. Livingstone.
} 


\section{Lawrence}

EXPERIMENTAL PHYSIOLOGY

How then was this world of the general physician, or possibly the chest physician, diagnosing and treating the classic valvular diseases, transformed into one with a different cardiological consciousness? At first sight, a demographic answer seems possible. The early years of this century witnessed a continuing decline in incidence of the major infectious diseases, and doctors were seeing a different pattern of morbidity. Bacteriologically-inspired investigations drew attention to the various forms of endocarditis; 1909, for example, was the year of Osler's classic paper on chronic endocarditis. ${ }^{44}$ Similarly, a relation between syphilis and aortic disease had been demonstrated. Patients with such diseases, together with those suffering from the newly recognized syndrome of thyrotoxic heart disease or diphtheritic carditis, might be thought of as forming a potential field of cardiological practice. Yet such a demographic answer simply begs the question of why it was that such disorders did fall within the purview of an emerging cardiological consciousness.

The crucial factor in the transformation was a new clinical perception of the heart. Instead of being interested in the statics and mechanics of the heart's action and the natural history of valvular disease, what began to matter to clinicians was the heart's dynamics; what the heart could do. What the heart could do, in turn, was held to depend on its unique physiological properties. There was thus a shift from pathological anatomy to pathophysiology and from an ontological to a physiological concept of disease. From the old cardiological perspective, a physician approached a patient who had a "disease", such as mitral stenosis or aortic incompetence, which had produced cardiac decompensation. The physician's skill lay in diagnosing the "disease", and showing how the signs approximated to an ideal natural history. He then treated the decompensation. The new cardiology involved a revolution in this perspective. The clinician perceived a patient with multiple indications of a "failing" heart owing to changes in one or more of its muscular properties. ${ }^{45}$ The physician's task was thus to elucidate what these changes were and make a prognostic assessment of the patient in terms of the heart's capacity to deliver blood. The state of the valves was simply another factor, and often a minimal one, influencing this assessment.

The practitioners of this new cardiology, of course, still elicited the physical signs of anatomical change in the heart, but this was not the goal of bedside practice. Such structural knowledge only partially helped to account for the information that really mattered, the physiological indices of cardiac efficiency. The site and intensity of a murmur were less important than the patient's symptoms, notably pain or dyspnoea, especially as they changed in time and in different situations. The most important clinical signs were those such as heart rate and rhythm, which referred to the performance, not the structure, of the cardiac muscle.

The distinct intellectual shape of the subject suggests that one of the origins of the new cardiology was the use by clinicians of concepts borrowed from experimental

44 William Osler, 'Chronic infectious endocarditis', Quart. J. Med., 1909, 2: 219-230.

${ }^{45}$ In 1912, Clifford Allbutt pondered on the increasing use of the term "heart failure" and asked whether "the new phrase may be a shadow thrown by some shift of position-whether clinical or pathological-in our view of the heart and its functions" (op. cit., note 17 above). John Harley Warner has suggested to me that in the American context similar changes in the objects of clinical cognition were tightly linked to a shift from "natural" to "normal" in clinical language. 


\section{The "new cardiology" in Britain 1880-1930}

physiology, and indeed such a borrowing was proclaimed by the clinicians themselves. It has been pointed out that, during the late nineteenth century, the teaching of anatomy and physiology in many English medical institutions remained largely in the hands of clinicians whose bedside orientation gave these disciplines a strongly practical bias. This is not suprising, since these subjects were considered as the foundation of a clinical art, not the theoretical prerequisite for an applied science. But, at the same time as this traditional teaching went on, a new breed of full-time, experimental physiologists was establishing itself, notably under Michael Foster at Cambridge. Many clinicians, though, saw in these subjects little of relevance to their discipline, and indeed, experimental physiologists were often hard put to show how their research could impinge on the treatment of the sick.

By the early years of this century, however, physicians were qualifying who had been educated in the experimental disciplines in the 1880 s and 1890 s, and some of these were men clearly thinking of bedside medicine in terms of pathophysiology, not simply pathological anatomy. Significantly, some of the most original English physiological work had been on the heart. In 1883, the physiologist W.H. Gaskell described the regular rhythmical contraction, independent of nervous or artificial stimulation, of a strip of ventricular muscle isolated from the tortoise's heart. ${ }^{46}$ It was not long after this that Gaskell's interpretation of his demonstration was accepted by the scientific community. This meant that the supporters of the myogenic theory of the heart's contraction had triumphed over the neurogenic school. In other words, it was accepted that the heart muscle had the innate capacity to produce rhythmical contraction rather than needing recurrent external nervous stimulation.

Gaskell's finding was complementary to, and an extension of, the earlier work of another Cambridge physiologist, George Romanes, who, like Gaskell, was a protégé of Michael Foster. Romanes had examined the contraction of the swimming-bell of the medusa or jellyfish, and had cut spiral strips from the bell and observed how the waves of contraction passed down them until they were unable to pass a particularly narrow section. This interruption Romanes termed "block". In 1882, Gaskell described a suspension method of examining the frog's heart: "Its principle consists in the fixing of a point of the heart and registering the contraction of any two points which are separated by that fixed point the recording being effected by means of two levers attached by silk threads to the two parts of the heart thus separated."47 In this paper, and in another of 1883, Gaskell showed that the ventricle followed the contraction originating from the venous sinus in the auricle, but that, in the absence of the stimulus, for example by "blocking" its transmission, an independent ventricular rhythm would arise. The sinus was simply the fastest paced centre of spontaneity.

In 1935, Charles Sherrington, also a pupil of Foster, wrote: "The question which ... [Romanes] put to the swimming bell and answered from it, led it is not too much to say to the development of modern cardiology. Medusa swims by the beat of its bell, and Romanes examining it discovered there and analyzed the two

${ }^{46}$ W.H. Gaskell, 'On the innervation of the heart with especial reference to the heart of the tortoise', $J$. Physiol., 1883; 4: 43-127. For a contextual account of Gaskell's work, see Geison op. cit., note 23 above.

${ }^{47}$ Ibid., p.48 


\section{Lawrence}

phenomena now recognized world-over in the physiology of the heart, and there spoken of as the "pace-maker" and "conduction-block". Romanes' work ... directly inspired Gaskell's on the heart, the latter proving in its turn and in due course a stepping-stone to James Mackenzie and to Sir Thomas Lewis." ${ }^{48}$

\section{CLINICAL APPLICATION}

This remark of Sherrington's hit the historical nail on the head, even as it simultaneously struck a blow for the cause of experimental physiology. ${ }^{49}$ James Mackenzie was a Scot and a general practitioner in Burnley at the end of the last century. He began his study of the heart in the 1880 s. The subject, method, and aim of Mackenzie's work was entirely clinical. His intention was to examine his patients' symptoms over as long a period as possible in order that a full history of their diseases might be compiled. As part of this goal, he tried to develop clinical techniques whereby the origin of symptoms could be discovered, so that the benign ones could be separated from the malignant, in order that, ultimately, patients could be given a correct prognosis. The whole thrust of Mackenzie's approach was to establish general practice as a seat of clinical research. But the picture that is often painted of the lonely clinical researcher in general practice, even though there is some truth in it, should not be allowed to obscure a fundamental issue. Mackenzie was extremely well read in experimental physiology and was at this time in correspondence with such physiologists as Sherrington, John Langley, and C.S. Roy. ${ }^{50}$ Although Mackenzie's goal was clinical, his thinking was physiological.

One of the symptoms which, to Mackenzie, seemed an important key in the assessment of his patients was irregularity of the pulse. In order to investigate this, he first used a Dudgeon sphygmograph and then a polygraph devised by himself. ${ }^{51}$ Now, the polygraph as used by Mackenzie is a device for repeating at the bedside Gaskell's experiment of 1882 on the isolated heart. But whereas Gaskell could record directly, on a kymograph, from the auricles and ventricles of an experimental animal, Mackenzie had to record the contraction of these chambers indirectly, with an instrument recording the pressure waves of the arterial and venous blood. The polygraph, of course, uses the same recording principle as the kymograph; it makes a tracing on moving paper, a temporal sequence of events being recorded for later analysis. The object of Mackenzie's examination, therefore, like that of Gaskell and

\footnotetext{
${ }^{48}$ C.S. Sherrington, Edinb. med. J., n.s., 1935, 92: 397, quoted in Richard D. French, 'Darwin and the physiologists or the Medusae and modern cardiology',J. Hist. Biol., 1970, 3: 253-274. My analysis in this last section borrows a great deal from French's invaluable paper. See also Walter Langdon-Brown, 'W.H. Gaskell and the Cambridge Medical School', Proc. R. Soc. Med., 1939, 33: 1-10.

${ }^{49}$ In other words, I believe Sherrington was correct in suggesting that the cardiologists of the early twentieth century did employ concepts produced within experimental physiology. However, I do not see the necessary connexion in this regard, which Sherrington did. Clinicians did not have to adopt these concepts. Sherrington, however, was making a strong claim for the relevance of the basic sciences to modern medicine by invoking the ineluctable factor: "development". See a similar claim by C.J. Wiggers, cited and analysed in Geison, op. cit., note 23 above.

${ }^{\text {so }}$ A. Mair, Sir James Mackenzie M.D. 1853-1925, general practitioner, Edinburgh, Churchill Livingstone, 1973, p.89. Mackenzie said to Langdon-Brown, "The further I go the more I realize Gaskell is the man." Langdon-Brown op cit., note 48 above.

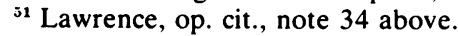




\section{The "new cardiology" in Britain 1880-1930}

Romanes, was the performance of the cardiac muscle. But Mackenzie did it at the bedside, whereas they had done it at the laboratory bench.

Through his analysis of the jugular venous and radial pulses, Mackenzie made prognostically useful distinctions between what he called the "youthful type of irregularity" or sinus irregularity, the "adult type of irregularity" or simple extrasystoles, and the ventricular type of venous pulse later associated with atrial fibrillation. ${ }^{52}$ The wider significance of Mackenzie's analysis, however, is that he was conceptualizing the heart a new way. The object of his attention was no longer a static visual image, a picture of a damaged valve, which could be seen on the page of a textbook or in the post-mortem room. Rather, it was ever-changing function, and, if visual at all, it was not a moving picture of the heart muscle (which would still be anatomical), but the effects of this movement, a tracing. ${ }^{53}$ Only by using such concepts were descriptions such as heart-block (to which, of course, may be attributed an anatomical seat) meaningful. Such an approach entailed that clinicians should perceive the patient in an entirely new way.

For Mackenzie, what mattered about the heart clinically was what he called the reserve force of its muscle, physiologically speaking its capacity to maintain the correct degree of tonicity, contractility, etc., to produce a normal circulation. "Heart failure", he wrote later in his textbook, "is simply the inability of the heart muscle to maintain the circulation." Such inability was always caused by "premature exhaustion of this reserve". From this point of view, valvular disease or hypertension were only important "as a source of embarrassment to the heart muscle". ${ }^{54}$ Heart failure, therefore, was the inability of the heart to deliver blood to the tissues. This account, the forward pressure theory of heart failure, considered diminished cardiac output as the defining feature of failure, not back pressure owing to the accumulation of blood behind a damaged valve. Clinically, Mackenzie's theory meant that symptoms and signs were valuable in so far as they pointed to the functioning of the heart muscle, the degree of embarrassment the heart was suffering or would suffer at some future date. Organic change of itself was of no importance. This view in one form or another was held by some of the most original thinkers in British clinical medicine for the first three decades of this century.

There is a well-known paradox about Mackenzie's work which distinguishes him from most of the men who adopted his views. Mackenzie believed that only in

\footnotetext{
${ }^{32}$ There are problems in the terminology used at the beginning of the century which require a great deal of further research. For present purposes it is sufficient to note that by the end of the first decade of this century a few clinicians agreed on these clinical distinctions and their prognostic significance.

${ }^{53}$ It is my impression that many late nineteenth-century textbooks on the heart contain a great number of "naturalistic" anatomical illustrations. Some, of course, contain sphygmographic tracings, but these are of pathological states such as aortic stenosis and the details of the curves are to be understood by reference to the morbid anatomy that produced them. Conversely, books produced by the new cardiologists, although they contain a few anatomical illustrations, are filled with tracings, the details of which do not refer to particular morbid anatomical sites.

54 James Mackenzie, Diseases of the heart, London, H. Frowde, 1908, pp.2-3. Mackenzie was at pains to point out that this was not the same thing as the old failure of compensation, for "this term embraces a great variety of definite forms of heart failure", for example, a failure of tonicity or contractility. "The nature of some forms of heart failure in consequence of long-continued high arterial pressure', Br. med.J., 1906, ii: 1007.
} 


\section{Lawrence}

general practice could proper research be carried on. Hospital medicine and specialization he saw as necessary evils. Second, Mackenzie saw his instruments, like the polygraph, as tools of research for elucidating the nature of symptoms. Once the pathological import of these symptoms had been determined, he believed that the instruments could be jettisoned and that in the future simple sensory examination of the patient would suffice. The paradox, of course, is that Mackenzie's dynamic approach to cardiac symptoms helped create the very specialization, hospital-centred practice and "technological fix" that he deplored. "I fear the day may come", he reportedly said, whilst still a general practitioner in Burnley, "when a 'heart specialist' will no longer be a physician looking at the body as a whole, but one with more and more complicated instruments working in a narrow and restricted area of the body." 55 This view might have been echoed by many clinicians of the old school in the great London hospitals.

\section{THE NEW CARDIOLOGISTS}

By the early years of this century, Mackenzie's work had become known to a small but influential group of British medical men. In 1902, Clifford Allbutt had reviewed Mackenzie's book on the pulse and had written that " . . .today, from the Galiliee of Burnley in Lancashire, comes a new teacher to prove to us that our content was shallow enough; and in an important work he has lifted the whole subject into a fresh light and into a larger aspect". ${ }^{56}$ In 1903, the young anatomist, Arthur Keith, began to correspond with Mackenzie, and later visited him. In that year, the enthusiastic Keith wrote to Mackenzie about one of his ideas, pointing out the lessons to be drawn from experimental physiology for clinicians of the old school: "The ventricle as leader in the cardiac cycle will waken the old fogies up, yet the work of Gaskell etc. prepares the way for you does it not!"57 In 1905, the newly arrived Regius Professor of Medicine at Oxford, William Osler, visited Mackenzie in Burnley. ${ }^{58}$ The following year, Arthur Cushny, professor of pharmacology at University College, also made the trip north, where he discussed with Mackenzie the experimental production of atrial fibrillation in the dog. ${ }^{59}$

\footnotetext{
${ }^{55}$ Mair, op. cit., note 50 above, p.107. W.F. Bynum has pointed out to me one of the interesting paradoxes of the "new cardiology". I have tried to argue that the formation of a new object of clinical cognition was integral to the growth of a new hospital-based speciality. Yet implicit (and explicit for Mackenzie) in the new cardiology was the notion that the sort of brief diagnostic encounter of the hospital was of little value in the assessment of the long-term functioning of heart muscle.

${ }^{56} \mathrm{Br}$. med. J., 1902, ii: 250 . That Allbutt was the reviewer is attested by Rolleston, op. cit., note 18 above, p.151, where it is also stated that Mackenzie remarked that the review "brought him out".

${ }^{57}$ Quoted in Mair, op. cit., note 50 above, p.132. In 1907, of course, Keith, with Martin Flack, described "a remarkable remnant of primitive fibres persisting at the sino-auricular junction [at which] ... the dominating rhythm of the heart is believed to normally arise", in a paper entitled 'The form and nature of the muscular connections between the primary divisions of the vertebrate heart', J.Anat. Physiol., 1907, 41: 172-189. Rolleston later used this discovery to invert the causal arrow and show how basic science had been "stimulated by the needs of the new cardiology" (op. cit., note 7 above p.7). According to his own account, Keith's enquiries were certainly fertilized by Mackenzie's research. See Sir Arthur Keith, An autobiography, London, Watts, 1950, pp.253-265.

${ }^{58}$ Cushing, op. cit., note 32 above, p.698. Osler visited with A.G. Gibson, one of the founder members of the Cardiac Club. He is not to be confused with the Edinburgh physician, G.A. Gibson, with whom Mackenzie corresponded (see Mair, op. cit., note 50 above, p.180).

${ }^{39}$ Sir John McMichael, 'Sir James Mackenzie and atrial fibrillation-a new perspective', J.R. Coll. gen. Practnrs, 1981, 31: 402-406. It was Cushny who suggested that the experimental fibrillation seen in the
} 


\section{The "new cardiology" in Britain 1880-1930}

More important for clinical medicine, however, was the way in which Mackenzie's techniques and approach were adopted by a few clinicians practising in hospitals in various parts of the country, notably outside London. In some cases, they were encouraged by personal friendship with the sage of Burnley. Significantly, too, they were often men who had a particular interest in experimental physiology. John Hay, for example, who had worked with Sherrington, was a physician at the Liverpool Royal Infirmary and a personal friend of Mackenzie. Beginning in 1900, Hay published numerous papers on heart disease, notably concerning himself with the arrhythmias. In 1909, he published Graphic methods in heart disease, with an introduction by James Mackenzie. ${ }^{60}$ In 1905, Hay reported a case of bradycardia in which polygraph tracings showed heart-block to be present. ${ }^{61}$ In the same issue of the British Medical Journal, he and five other authors commented on a paper dealing with degeneration of the heart. Hay's commentary was entirely characteristic of the new cardiology. Alone of the six, he reported the use of the polygraph in the investigation of this disorder. He concluded with a denial of the relations between structure and function in a manner that distinguishes the new approach; "What I would specially like to emphasize is that the onset of marked symptoms is largely independent of the myocardial degeneration and is synchronous with the onset of abnormal inception of rhythm." ${ }^{\circ 2}$ In other words, the degree of anatomical damage to the heart which the physician could infer should not be the basis for making an assessment, what mattered was what the heart was doing.

Another physician quick to take up the new approach to the heart was William Ritchie in Edinburgh. In 1905, he took polygraph tracing in a case of heart-block with an unusual rhythm, and in 1910, he published an account of the electrocardiographic investigations of the same case, naming the disorder auricular flutter. In 1914, he published a monograph on the subject. ${ }^{63}$ In Birmingham, in about 1909, Joseph Emanuel, who became an authority on auricular fibrillation, began working first with the polygraph and then with the newly invented electrocardiograph. In 1910, Emanuel reported a case of heart-block, drawing attention to the discrepancies between the symptoms and the evidence of the presence of morbid anatomy “ . . . in this case the history and the symptoms would

laboratory might be the same condition that gave rise to the clinical state of the total irregularity of the pulse.

${ }^{60}$ For an account of Hay and a bibliography, see Maurice Campbell and E. Wyn Jones, 'John Hay', Br. Heart J., 1959, 21: 573-577.

${ }^{61}$ John Hay, 'The pathology of bradycardia', Br. med. J., 1905, ii: 1034-1036. Hay could find nothing at necropsy and sent the heart to Keith, a practice he repeated a year later when he required a report on the auriculo-ventricular bundle ('Stokes-Adams disease and cardiac arrhythmia', Lancet, 1906, ii: 127).

${ }^{62}$ 'A discussion on the diagnosis and treatment of degeneration of the heart apart from valvular' disease', Br. med. J., 1905, ii: 1023-1036. Compare this with the remark of J. Dreschfeld in the same: "In many cases we have to deal with functional derangement and not an organic degeneration of the heart. This is beyond the scope of this discussion" (p.1023). The notion that one might have to deal with either/or became anathema to many of the new cardiologists.

${ }^{63}$ William Ritchie, 'Complete heart-block, with dissociation of the action of the auricles and ventricles', Proc. R. Soc. Edinb., 1905-6, 25: 1085-1091. William Jolly and William Ritchie, 'Auricular flutter and fibrillation', Heart, 1910, 2: 177-221: William Ritchie, Auricular flutter, Edinburgh, W. Green, 1914; [obituary], Br. med. J., 1945, i: 238. 


\section{Lawrence}

seem undoubtedly to indicate the existence of a severe heart lesion [but] the physical signs show no sufficient evidence of this". ${ }^{64}$

It is generally acknowledged, however, that Mackenzie's most important influence was on the man who, in time, and perhaps paradoxically, came to be identified with the new cardiology, Thomas Lewis. Lewis, a Welshman, entered University College Hospital Medical School in 1902. Significantly, he had a keen interest in experimental physiology and, by 1904, was a member of the Physiological Society. Already by 1906, he had published experimental work on the pulse and blood pressure. He was, therefore, even before he met Mackenzie, interested in the dynamics of the cardiovascular system. During 1907-8, he worked in the most famous physiological laboratory in England, that of E.H. Starling at University College London. ${ }^{65}$

In 1908, Lewis met Mackenzie, who had moved to London in the previous year. The medical significance of their meeting was that Lewis took up Mackenzie's clinical polygraphic work, and, using the newly invented electrocardiograph, explained Mackenzie's results in terms of electrophysiology. In 1909, Lewis identified auricular fibrillation with the cardiac disorder which gave rise to Mackenzie's ventricular venous pulse. In 1911, his monograph Mechanism of the heart beat was published and dedicated to James Mackenzie and Willem Einthoven, the inventor of the string galvanometer type of ECG. ${ }^{66}$

The years between 1910 and 1914 were crucial in establishing the new cardiology. At the end of the first decade of the century, Mackenzie and his approach to the study of the heart were probably unknown to many ordinary practitioners. J.W. Linnell, who, in 1909, was Resident Medical Officer at Mount Vernon Hospital where Mackenzie was on the staff, recalled:"I knew absolutely nothing of the man or his work-as did few medical men in London, whatever their rank and standing". ${ }^{67}$ A few years later, after the publications of Mackenzie, Lewis, and others, the profession was noticing that there were changes afoot. Robert Marshall, in 1913 the first Resident Medical Officer at the new National Hospital for Diseases of the Heart, wrote "Sir James Mackenzie was our prophet". ${ }^{68}$ By the time of the Great War, the journals were full of references to the new subject.

\footnotetext{
${ }^{64}$ J.G. Emanuel, 'On a case of heart-block', Lancet, 1910, i: 856-858. Emanuel's study of fibrillation was Auricular fibrillation, Birmingham, Cornish Bros., 1926. On Emanuel, see O. Brenner, 'J.G. Emanuel', Br. Heart J., 1958, 20: 579-581. Brenner records Emanuel's uniqueness in the Midlands in using the ECG and the polygraph.

${ }^{65}$ A.N. Drury and R.T. Grant, 'Thomas Lewis 1881-1945', Obituary Notices of Fellows of the Royal Society, 1945, 5: 179-202.

${ }^{66}$ A. Hollman, 'Thomas Lewis-the early years', Br. Heart J. 1981, 46: 233-244. I have tried, where possible, in this account to escape from identifying the new cardiology with Lewis and Mackenzie, and attempted to discuss the subject in terms of a community of physicians with a new perception of heart diseases. Indeed, a good case can be made out for the atypicality, in different ways, of Lewis and Mackenzie. In this regard, see the intriguing paper by Sir John McMichael, A transition in cardiology: the Mackenzie Lewis era, Harveian Oration 1975, London, Royal College of Physicians, 1976. See also Joel Howell, " "Soldier's heart": the redefinition of heart disease and speciality formation in early twentieth-century, Great Britain', this volume, pp. 34-52.

${ }^{67}$ J.W. Linnell, 'Some recollections of Sir James Mackenzie', in Mair, op. cit., note 50 above, p.240. This seems a little curious: intelligent reading of the $B r$. med. $J$. during the first decade of the century would have made readers aware of Mackenzie. However, the reference to his anonymity in London may be significant. But cf. Mair, p.221.
} 


\section{The "new cardiology" in Britain 1880-1930}

During the second decade of this century, increasing numbers of physicians turned their attention to the new perspectives opened up by dynamic studies of the heart. John Marshall Cowan, for instance, worked in Glasgow, where he became Professor of Medicine. In 1914, he published a textbook on diseases of the heart. He acknowledged the work of many authors, including Mackenzie, but not Lewis. The first paragraph of the preface referred to the "great advances" which had been made in the knowledge of diseases of the heart, and it cited the new technologies. The plan of Cowan's book exemplifies the changes that had occurred in the study of the heart. Of the twenty-four chapters relating specifically to the heart, the first twelve were devoted to the normal and abnormal manifestations of rate, rhythm, contractility, and conductivity. Although, of course, the features of "classic" valvular diseases were described, they were approached from the perspective of cardiac failure. ${ }^{69}$

Gradually, other active provincial physicians adopted the new approach. At Newcastle, William Hume introduced the ECG into the Royal Victoria Hospital in 1913. His interests turned on the cardiac rate and rhythm and, after 1914, he published regularly on cardiac irregularities which were demonstrable with the polygraph and ECG. ${ }^{70}$ In Ulster, John Macllwaine was using the ECG at least as early as $1914 .^{71}$

The case for the "new cardiology" was summed up in George Sutherland's Lumleian lectures of 1917. Sutherland, like Mackenzie, was a Scot, and had a longstanding interest in heart disease. In 1914, he had published The heart in early life, a work lavishly illustrated with polygraph traces. ${ }^{72}$ The challenge of showing the originality of the new cardiology and also of affirming its links with the past was immediately evident in Sutherland's lecture, for he began: "To many of us it has been made clear that within recent years there has been a revolution in the domain of cardiology"; he followed with the more humble accretionist perspective, "It has really consisted in the filling-in of more gaps in our previous knowledge". The subsequent tone of the lecture, however, underlined the revolutionary views of moderns. He discovered the lineage of the new cardiology not in nineteenth-century clinical medicine but by linking the names of Gaskell and Mackenzie, a relationship that was frequently made at this time.

The old cardiology, said Sutherland, considered the heart as having only one function, "contractility". But, he went on, physicians must also consider rhythmicity, excitability, conductivity, and tonicity, which were formerly held to be the preserve

\footnotetext{
${ }^{68}$ Marshall, op. cit., note 36 above.

${ }^{69}$ John Cowan, Diseases of the heart, London, Edward Arnold, 1914. The chapters on the ECG were written by Ritchie.

${ }^{70}$ On Hume and references to his polygraphic and ECG studies, see W.G.A Swan, 'Sir William Hume', Br. Heart J., 1906; 22: 426-428.

${ }^{71}$ J.E. MacIlwaine, 'Electrocardiographic method of examining the heart beat', Trans. Ulster Med. Soc., 1913-14: 132-141. Macllwaine, however, on the basis of this article, cannot be counted as a new cardiologist. The paper is a simple description of the ECG, and an account of its value in the diagnosis of a number of simple rhythmic disturbances. The paper contains no programmatic statements, only the surprising "The ECG is really a myocardiogram".

${ }^{72}$ In this book, Sutherland's position is totally that of the new cardiology except that he makes a distinction in the case of children between "organic" and "functional" disorders. G.A. Sutherland, The heart in early life, London, Henry Frowde, 1914.
} 


\section{Lawrence}

of the physiologist but are actually of importance at the bedside. Clinically, he noted, the old cardiology thought of the heart as having two parts, right and left, each with their own diseases and sequelae, notably right- and left-sided failure. In the past, he said, "students learned to classify cases according to the valve affected". Perhaps anticipating criticism, he added: "It may be said that the best writers and teachers held no such views." However, having made this concession, he continued: "the effect of this teaching and writing was to impress permanently on the student the idea that valvulitis is the important lesion in organic heart disease." The new cardiology, like the old, also has a twofold division of the heart, but in this case it is into an "auricular part and a ventricular part. There is also, he added, "a third portion of the heart of great clinical importance known as the junctional tissues". He then expounded a view of cardiac disease close to that of Mackenzie: "So we reach the conclusion, that whatever the disease or disturbance present, the important point to be considered is the effect on the driving power of the left ventricle." This, as he acknowledged, was Mackenzie's philosophy of the reserve force. Such a view had important consequences. The first was to minimize the role of valvular lesions. "The view", he said, "that valvulitis is the central factor in heart disease has proved misleading." It led, he said, to the erroneous opinion that heart failure was the mechanical result of back pressure behind a damaged valve: "The theory of back pressure was held to be the explanation of cardiac failure in such different lesions as mitral stenosis, mitral regurgitation, and aortic regurgitation." Sutherland, however, insisted that what happens in these instances is that when some superadded work is put upon the heart, such as follows the onset of fibrillation, "in all cases the signs of cardiac failure are brought about by a diminution of the forward pressure exerted by the left ventricle". To the clinician who adopts this view of the heart's action, he averred, what is of primary importance is the estimation of cardiac power by reference to the patient's symptoms, especially those that are manifest on effort. "We have therefore come to regard symptoms as the most reliable evidence of impaired action of the heart." The clinician, however, needs to supplement this symptomatic assessment by examination with the ECG and the polygraph. Heart murmurs as clinical signs were of little help or misleading. Sutherland went on to challenge the significance given to another change associated with valvulitis, dilatation of the heart. In the old cardiology, dilatation was always a sign of cardiac weakness. But, drawing on the work of Starling, Sutherland suggested that, "a tired heart must dilate in order to carry on the same work as a fresh heart". Thus dilatation should not necessarily be viewed as a sign of cardiac failure but sometimes as "one of the means by which the cardiac muscle meets a disturbance or difficulty in connexion with the circulation". ${ }^{73}$

Sutherland's account owed much to Mackenzie, who, in his text of 1908 on Diseases of the heart, had written of valvulitis: "Valvular defects will not be studied as a specific affection to be considered in themselves, but rather as a source of

${ }^{73}$ G.A. Sutherland, 'Modern aspects of heart disease', Lancet, 1917, i: 401-406, 437-442, 477-482. Starling published several papers around this time, later summed up in his The Linacre lecture on the law of the heart given at Cambridge 1915, London, Longmans Green, 1918. See Callahan et al., op. cit., note 5 above, pp.113-138. 


\section{The "new cardiology" in Britain 1880-1930}

embarrassment to the heart muscle in its work". ${ }^{74}$ Lewis, in 1919 , was even more explicit about the role of morbid anatomy: "The question, is there or is there not organic disease? is not a necessary question. A man who is wise cares little whether he has structural change in his heart or not". ${ }^{75}$ A specific application of this view can be found sixteen years later in his textbook Diseases of the heart: "The undue emphasis placed upon diseases of the cardiac valves in diagnosis was the chief reason why the prognosis of heart disease long remained so very unsatisfactory." failure, Lewis held, is simply "the inability of the heart to discharge its contents adequately". ${ }^{77}$

This new cardiology, which relegated heart murmurs to the bottom of the league table and stressed the functional assessment of the heart, did not, of course, immediately sweep the field. For one thing, it was the enthusiastic pursuit of only a few physicians, as suggested, for example, by the tardiness with which ECG machines came into use. $^{78}$ In general, older physicians continued to rely on the familiar categories. Military doctors in the First World War still discharged men on one of two grounds, VDH or DAH, a dichotomy that Lewis called "preposterous". ${ }^{79}$ This simple division of heart disease, valvular and non-valvular, was the very one the new cardiologists were trying to reject.

But opposition to the new cardiologists was not only of the inert sort, that is, the persistence among the bulk of the profession of traditional practices. There was also active doubt among men of the older school who understood the new cardiology, and indeed had initially welcomed it. Clifford Allbutt, for instance, who had hailed Mackenzie's work, remained doubtful that the new cardiology could deliver the goods. In 1912, he gave an address on heart failure. He began by accepting that the reserve of the heart was a crucial feature in giving rise to symptoms. But then he poured cold water on all attempts to achieve a measure of it: "of this reserve ... we have no scientific measure; the microscopist cannot detect it, the clinician has no valid tests for it." ${ }^{80} \mathrm{He}$ then declared that he favoured the older view. In valvular

${ }^{74}$ Mackenzie, op.cit., note 54 above, p.3.

${ }^{75}$ Thomas Lewis, 'On cardinal principles in cardiological practice', Br. med. J., 1919, ii: 621-625. I have disobeyed Lewis here, for he continued "I place this statement in a context from which it is not to be removed." Lewis simply meant that structural changes were of no importance if they did not interfere with a person's life, and the clinician therefore should not use signs of their presence to draw the conclusion that the patient is sick. See also in this article Lewis's remarks on valvular disease. See also Lewis on 'Certain physical signs of myocardial involvement', ibid., 1913, i: 484-489, where he says, "The valve and the pericardial sac are relatively but trivial appendages".

${ }^{76}$ Thomas Lewis, Diseases of the heart, London, Macmillan, 1933, p.143. "Anatomy", he said in the work, "fails as a chief basis of thought where heart disease is concerned" (p.vi).

${ }^{77}$ Ibid., p.l.

78 Joel Howell has suggested to me that the use of the ECG was not necessary to the establishment the new cardiology, which could, and did, exist without it. I am sure this is correct; however, some practitioners perceived the use of it, and other technologies, as a prerequisite to the successful pursuit of the discipline. Lewis, of course, wrote a paper, 'Electrocardiography and its importance in the clinical examination of the heart', Br. med. J., 1912, i:1421,1479; ii: 65 . He was later to change his views. See Lewis, op. cit., note 76 above, p.vi.

${ }^{79}$ Lewis, op. cit., note 75 above.

${ }^{80}$ Allbutt, op. cit., note 17 above, p.653. Allbutt and Mackenzie had had some slightly warm correspondence in the pages of the Br. med. J. the previous year. Allbutt was annoyed by Mackenzie's calling attacks of recumbent dyspnoea in patients with heart disease "Cardiac asthma" (Br. med. J., 1911, ii: 1040,1135). The term had been coined by James Hope. See Nathan Flaxman, 'The Hope of cardiology', Bull. Inst. Hist. Med., 1938, 6: 1-21. 


\section{Lawrence}

diseases, he said, such things as reserve did not matter: "the conditions are frankly mechanical ... generally speaking it is the static structures rather than the dynamical potentials which determine the issue." Further, in non-valvular disease no method had proved of value in estimating dynamics: "The X-ray method, and . . . the method of the electrocardiogram ... were supposed to place in our hands tests of myocardial dynamics; but hitherto we have had to be content with facts which, however interesting, do not give us the intimate criterions we desire." ${ }^{81}$ Allbutt also tackled Mackenzie's belief that symptoms could give an early warning of failing cardiac reserve, and dismissed them as unhelpful. In another paragraph on the pulse he went on: "It has ... been ... asserted again and again that the profounder changes in the myocardium are betrayed by an irregular pulse but as our experience of cardiac disease has widened we have learnt that in the rhythms we have rarely any criterion of cardiac values." 82

Such a pronouncement attacked much that was central to the new cardiology. Allbutt's point, however, was simply that, although on occasions a correlation between clinical signs and cardiac effectiveness could be found, more often than not there was no good clinical guide to the functional state of the heart.

Not surprisingly, Allbutt's remarks drew the fire of the new school, on this occasion from Thomas Lewis. Lewis agreed that traditional clinicians and morbid anatomists had failed to provide a satisfactory account of the heart but, he went on, "there is a third school ... the clinicians who attempt a closer study of the morbid physiology of the living heart". This school, he declared, was solving the problems of heart failure. "Who cares", he said, "whether in any instance a lesion can be found to account for irregularity. The irregularity itself is evidence that the cardiac muscle has suffered functional change." 83

That the new study of the heart was not simply perceived by contemporaries as a "filling-in" of the gaps in former knowledge can be gauged from the response to Sutherland's Lumleian lectures. A week after the first lecture, Frederick Smith, a London physician, wrote criticizing Sutherland for "an inaccurate representation of what is old" and suggesting that Andrew Clark and Henry Sutton, both nineteenth-century physicians, "knew as much as we do now" about irregularity and its effects, and also a "good deal" about "rhythm, excitability and tonicity". ${ }^{84}$ The Lancet in a mildly placatory editorial, suggested there "need be no quarrel with the older school" and that the insight of the past masters had been "distorted by subsequent teachers". However, the tone of the article remained thoroughly modern, implying that the previous twenty years had seen a clinical revolution, notably in the discovery of "the essential importance of clinical subjective symptoms". ${ }^{85}$ Letters commenting on the Lumleian lectures continued to appear

\footnotetext{
${ }^{81}$ Allbutt, op. cit., note 17 above, p.654. My italics.

82 Ibid., p.655.

${ }^{83}$ Thomas Lewis, Correspondence, Br. med. J., 1912, i: 757. Italics in original.

${ }^{84}$ Lancet, 1917, i: 555.

${ }_{85} 5$ 'Annotations', ibid., p.541. It should be noted that there is good evidence in some of the earlier writers to support the view that they minimized the significance of valvular lesions. Stokes remarked that their "determination is of comparatively trifling importance" (op. cit., note 9 above, p.132). Such a remark does not, of course, confer on him the same clinical perspective as a physician practising in 1917.
} 


\section{The "new cardiology" in Britain 1880-1930}

throughout the year, notably on the assessment of murmurs and on the nature of heart failure. ${ }^{86}$ In May, Mackenzie wrote a truculent response to earlier hostile correspondence but admitted bafflement as to the cause of heart failure in aortic regurgitation. ${ }^{87}$ The following week, the paediatrician Frederick Poynton replied with what seems like an implied sneer at Mackenzie's methods. "I am aiming at the arrest of the advance of heart disease in childhood.... This is a long affair, not so rapid, for example, as a polygraph tracing." ${ }^{88}$ A week later, E.H. Colbeck wrote that he hoped that someone would meet the challenge of the new cardiology "on behalf of the older school of cardiac clinicians". ${ }^{89}$ Within a week, his plea was answered by an impressive letter from the London physician, Alexander Morison. Morison defended the theory of back pressure, and saw his role as "maintaining the importance of the valvular factor in heart disease against exponents of the "new cardiology',"90 There was worse to come. Late in June, John Broadbent, no small fish in the cardiological pond, wrote criticizing "The modern conception of heart [which] seems to ignore the important fact that there is a right and left side of the heart, and that one may have failure either of the right or left ventricle not necessarily of both". In mitral stenosis, he added, the "disastrous effects of back pressure on the lungs . . . are self-evident". Broadbent also questioned another discovery sacred to the new cardiology: "I am", he said, "unable to accept in its entirety the doctrine of auricular fibrillation."91 Broadbent's meaning here is not entirely clear, something he possibly intended. The letter drew a scornful reply from Lewis. ${ }^{92}$

Later in the same year, Allbutt had moved even further from championing the new school and now considered himself as a member of the old. Of the new discipline he complained: "It is rather blind to the mass of clinical material . . gathered together from the days of Sénac and of Laennec to those of Balfour, Broadbent and clinical teachers happily still with us". A murmur, he said, "however remediable, cannot be a matter of indifference". The morbid anatomy of the heart was the baby that had been thrown out with the dirty bathwater of structural disease entities. "It is not safe to argue that so long as the heart is doing its work ... the murmur may be pardoned for its innocence." Mackenzie, he said, had "relied too much on superficial laboratory experiments". ${ }^{93}$ It is not surprising, of course, that when critics called into question

${ }^{86}$ Lancet, 1917 , i: $589,700$.

${ }^{87}$ Ibid., pp.820-821.

${ }^{88}$ Ibid., p.855. The response was not surprising; Mackenzie had been quite rude about Poynton the previous week.

${ }^{89}$ Ibid., p.892.

${ }^{90}$ Ibid., p.929. Munk records, "Morison's faith in simple clinical observation to the exclusion of the ancillary scientific methods then in process of development"' (G.H. Brown (editor), Munk's Roll. Lives of the Fellows of the Royal College of Physicians of London, vol. 4: 1826-1925, London, Royal College of Physicians, 1955, p.445).

${ }^{91}$ Lancet, 1917, i: 965. Broadbent was a St Mary's physician, who had helped his father, William, write Heart disease, London, Baillière Tindall \& Cox, 1897. See Munk's Roll, vol.4, op. cit., note 90 above, p.458.

${ }^{92}$ Lewis, op. cit., note 1 above.

${ }^{93}$ Lancet, 1917, ii: 172-173. For further debate on the issues see, for example, Harrington Sainsbury, 'The theory of "Back Pressure" as a consequence and as a cause of heart failure', ibid., pp.870-871. Sainsbury defended the theory, and added that "advances in cardiology . . . have not so enriched us up to the present that we can afford to forgo those older standards which have stood the test of time." 


\section{Lawrence}

the theories of the new cardiology they also doubted its methods. These, after all, were the techniques by which the new object of study-the living heart-was demonstrated. On the rhetorical battlefields of tradition versus innovation, morbid anatomy versus morbid physiology, art versus science, clinical technology was seen as a siren luring the less vigilant into false knowledge. One observer from the old school remarked: "there is a real risk that the information to be gained by increasing attention to graphic methods will arrest rather than advance our knowledge of the etiology of cardiovascular disorders."

One of the problems of the new cardiologists, therefore, was to assert their originality whilst trying not to offend tradition. Nowhere can this be seen more strikingly than in their historical account of their subject. Two contemporary histories were called The heart, old and new views and The heart past and present, and both were structured so as to have two different parts simultaneously asserting and denying continuity. ${ }^{95}$ The isolation some of the new school felt was captured by one in a chapter entitled 'The loneliness of the cardiologist'. ${ }^{96}$

\section{NEW PERCEPTIONS}

One of the interesting features of the new cardiology is that the concern of its practitioners with the functional capacity of the myocardium resulted in a characteristic perception of well-known cardiac symptoms and signs, notably high blood pressure and angina. The direct measurement of blood pressure was first systematically undertaken in the physiological laboratories of the late nineteenth century.$^{97}$ By the beginning of the twentieth century, sphygmomanometers of various sorts had been devised for performing this task at the bedside. ${ }^{98}$ Interestingly, however, clinicians, both old and new, to some extent ignored these devices and relied on the traditional method of estimating the tension of the pulse-a parameter that was usually, but not always, identified with blood pressure. Controversy over the use of instruments was common. In 1906, for example, in a discussion paper on blood pressure, G.A. Gibson wrote:"Those teachers who still oppose the use of our modern instruments of research in the investigation of blood pressure are on the same level as those who condemn the employment of such instruments as the opthalmoscope." In the same discussion a few pages further on, John Stevenson

\footnotetext{
${ }^{94}$ Chalmers Watson, 'A new school for the study of heart disease', Br. med. J., 1917, ii: 272. It should not be supposed, however, that all the spokesmen for the new cardiology insisted on instrumental examination. Both Lewis and Mackenzie clearly became sceptical towards the routine use of instruments. The attitude of the new cardiologists reproduced their ambivalent view of the past: instruments are essential for elucidating a new view of the heart, but in practice old clinical skills, properly used, should suffice. For a statement of exactly this position, see Edgar Lea, Heart past and present, New York, William Wood, 1919, pp. 276-277.

${ }^{95}$ H.L. Flint, The heart:old and new views, London, H.K. Lewis 1921; and Lea, op. cit., note 94 above. Fifty years later, the new cardiology would be incorporated into a seamless and untroubled history of “cardiology". See, for example, Terence East, The story of heart disease, London Dawson, 1957.

${ }^{96}$ Lea, op. cit., note 94 above.

${ }^{97}$ Blood pressure is another modern physiological entity which has been found to have a long prehistory of attempts to measure "it". But, as I understand the term, blood pressure as a concept came into existence only relatively recently.

${ }^{98}$ See the works listed in Christopher Lawrence, 'Physiological apparatus in the Wellcome Museum.3. Early sphygmomanometers', Med. Hist., 1979, 23: 474-478.
} 


\section{The "new cardiology" in Britain 1880-1930}

affirmed "for the practical physician, in the investigation of blood pressure the trained finger must be the ultimate appeal, and it is, I hold, sufficient". ${ }^{99}$ There are several remarkable points here. Notably, it is stated today that the feeling of the pulse, except in extreme cases, bears little or no relation to instrumental estimations of blood pressure. However, the opinion that the finger was sufficient can be found recurrently in the medical literature in the period 1900-30. Indeed, Thomas Lewis, writing in 1933, said:" the fingers should be trained to recognise a high tension pulse; for a pressure meter can hardly be used in routine practice". ${ }^{100}$ Now why was this? There were several reasons, the first of which was the endorsement of the traditional clinical skill of feeling the pulse. If the new cardiologists were changing perceptions of the heart, they were not intentionally iconoclastic. They sought to establish continuities as well as to make changes. Mackenzie, whose pronouncements were not without effect, always preferred older methods if the new did not seem to offer any advantage. In 1908, he wrote of the arterial pressure: "The trained finger is as yet the best guide we have in judging the pressure within an artery". ${ }^{101}$ But even when instruments were used, clinicians could not agree on what was being measured. As late as 1920, William Russell, Professor Emeritus of clinical medicine at Edinburgh, maintained that the practical value of the sphygmomanometer "lies not in providing an assured record of heart power in terms of blood pressure; [but] . . it supplies in the same patient ... a record of the condition and state of the arterial wall". ${ }^{102}$ Neither was there agreement as to which points either tactile, audible, or visible constituted systolic, mean, and diastolic pressures. Special instruments, oscillometers, were devised to estimate pressure by the fluctuation of the needle on the instrument, and physicians compared the claims of competing devices. At the National Heart Hospital in 1913, Robert Marshall remembered comparing "the figures of the Riva-Rocci sphygmomanometer with those of the Pachon oscillometer". ${ }^{103}$ When blood pressure was taken, it was commonly only the systolic that was registered. In 1914, MacWilliam drew attention to Korotkoff's little-used auditory method for determining diastolic pressures, and pointed out how much more important for physiologists the lower pressure was. ${ }^{104}$ But in 1919, Edgar Lea, very much a "new cardiologist", could only say, "The diastolic pressure is stated to have some value". ${ }^{105}$ But these minor skirmishes over blood pressure point to something rather more interesting. Simply that, in the terms of the new cardiology, blood pressure was not actually very important. The estimation of systolic pressure, Mackenzie wrote, "has been of little practical value". With advancing years, he suggested, the loss of arterial elasticity "necessitates increased force of ventricular

\footnotetext{
99 'A discussion of blood pressure in relation to disease', Br. med. J., 1906, ii: 996-1010.

${ }^{100}$ Lewis, op. cit., note 76 above, p. 230.

${ }^{101}$ Mackenzie, op. cit., note 54 above, p.89.

${ }_{102}$ William Russell, The sphygmomanometer its value in practical medicine, London, Baillière, Tindall \& Cox, 1921, p.123.

${ }^{103}$ Marshall, op. cit., note 36 above.

104 J.A. MacWilliam and G. Spencer Melvin, 'Systolic and diastolic blood pressure estimation with special reference to the auditory method', Br. med. J., 1914, i: 693-697. The physiologists were advising clinicians on the "desirability" of determining both pressures in 1905. See Percy M. Dawson, in op. cit., note 99 above, p.998.

${ }^{105}$ Lea, op. cit., note 94 above, p.89.
} 


\section{Lawrence}

contraction and therefore an increase of the pressure during ventricular systole". The heart accommodates to peripheral demand by calling on its "reserve". Hypertension was thus a physiological response-often an "esential" one. Unless it affected cardiac performance, it was of no importance. Even when it did affect the heart's work, said Mackenzie, it was more important to "place the patient under conditions that give the heart less work to do" than to give "vaso-dilators". ${ }^{106}$ Olser, in an address on high blood pressure in 1912, insisted "get it out of your heads, if possible, that the high pressure is the primary feature and particularly the feature to treat". ${ }^{107}$ Even Starling's work on the heart was interpreted by clinicians to mean that, in the absence of signs of failure, it did not matter how high the resistance was against which the heart worked. ${ }^{108}$ Harold Cookson, at Birmingham in 1923, remembered: "Blood pressure readings were taken as a routine but the part played by hypertension in causing heart failure was not realized."109 In Sutherland's Lumleian lectures, he did not even refer to blood pressure, and apparently had not taken it in the cases whose histories he recited. "Sphygmomanometrical observations", wrote Allbutt, "have proved so far, to be of no use in the detection of myocardial disease." ${ }^{110}$ New cardiologists felt dismayed that they were unable to use the work of physiologists: "... the facts relating to blood-pressure stimulated an enormous mass of observation, and, if we have to confess that such research has not carried us very far, this is not the fault of the physiologist, to whom we owe primarily its introduction."111 This is quite comprehensible. If clinical signs were important only as indices of cardiac efficiency, blood pressure was not very helpful. The systolic blood pressure, even when taken recurrently, presumably, in most cases returned a static or stable value. Such a reading, unlike a graphic analysis, gave no account of what was happening to the heart day by day or even second by second. Although it was a physiological parameter, it could not, in terms of the new cardiology, be used to interpret the changing state of the heart.

If blood pressure was not used as a sign of cardiac efficiency then angina most certainly was. It is a well-recounted piece of history that at different times throughout the nineteenth century and even before, various physicians had described an association between intense chest pain, coronary artery narrowing, the presence of coronary thrombi, and necrosis of cardiac muscle. It is also well known that the clinico-pathological syndrome of myocardial infarction or heart attack was not recognized by the medical community until the 1920s after the work of the American, James Herrick. Herrick used the electrocardiograph in the comparative cardiological backwater of Chicago to define this syndrome at the very time when London was the Mecca of electrocardiography. ${ }^{112}$

${ }^{106}$ Mackenzie, op. cit., note 54 above, pp.94-100

${ }^{107}$ William Osler, 'High blood pressure', Br. med. J., 1912, ii: 1173.

${ }^{108}$ Lea, op. cit., note 94 above, p.90.

${ }^{109}$ Cookson, op. cit., note 40 above. This, of course, is a "Whiggish" claim but this does not detract from its value as evidence as to the unimportance of blood pressure.

${ }^{110}$ Allbutt, op. cit., note 17 above, p.656.

${ }^{111}$ Lea, op. cit., note 94 above, p.48.

112 The most detailed account of this history is in J.O. Leibowitz, The history of coronary heart disease, London, Wellcome Institute for the History of Medicine, 1970. Leibowitz writes: "The belated recognition of infarction of the myocardium . . . has puzzled most historians in this field" (p.1). 


\section{The "new cardiology" in Britain 1880-1930}

It should now not be hard to see why this was so. Angina for Mackenzie and the new school was "exhaustion of the heart". ${ }^{113}$ Such exhaustion followed from any cause overtaxing the heart in the same way that dyspnoea was a symptom expressing failure of the lungs. The symptom was the final pathway by which a heart with valvular disease, fatty infiltration, fibrotic change, or coronary artery disease expressed its inability to cope. Angina, Mackenzie wrote in 1916, sometimes "develops with great severity and ends speedily in death. On the whole, these cases are rare .... When the changes are of the senile degenerative type there is always a history of cardiac inefficiency before the pain-as revealed by breathlessness on exertion." 114 Since what mattered was the functional origin of symptoms, what would now be diagnosed as myocardial infarction was only seen as an extreme form of muscle exhaustion. Herrick's description of the syndrome did nothing to alter this immediately. British physicians had their own clinical perspective. Sir Ian Hill remembered: "I personally saw my first patient with myocardial infarction in 1928. The diagnosis was made by a young clinical tutor A. Rae Gilchrist and the condition was one of which neither my Chief nor I had ever heard."115 Presumably, however, Hill had seen cases with angina so severe that they terminated in death? Within a dynamic cardiology simple clinico-pathological correlations were not considered. Symptoms were the signs of cardiac distress from whatever cause. It was axiomatic that angina, either chronic or sudden and even associated with death, pointed to a general functional failure which could arise from a variety of local embarrassments. The idea of simple clinico-pathological correlation, as in valvular disease, had become old-fashioned. What mattered now was the overall performance of the heart. It has been pointed out recently that Lewis used the ECG machine as a sophisticated polygraph, an amplifier of cardiac signals, not a transducer ${ }^{116}$ Used in this way, the ECG is a first-class tool for investigating arrhythmias, but essentially does little more

Leibowitz's position is, I think, that the "disease" existed in the past and, in one way or another, clinicians have described "it".

${ }^{113}$ Mackenzie, op. cit., note 54 above, p.43. I realize this cannot be the whole story. In 1910, Osler, a great morbid anatomist, delivered the Lumleian Lectures on angina pectoris. He described multiple morbid anatomical and functional origins for angina. Lancet, 1910, i: 697, 839, 947.

114 James Mackenzie, Principle of diagnosis and treatment in heart affections, London, Henry Frowde, 1916 , p.77. It is noteworthy that Cowan makes virtually no mention of angina as a cardiac symptom (op. cit., note 69 above).

${ }^{115}$ Hill, op. cit., note 39 above. "Coronary embolism", Allbutt wrote in 1924, "is happily rare. I have seen three cases" (Br. med. J., 1924, i: 828). But cf. Rodney Finlayson, 'Ischaemic heart disease, aortic aneurysms, and atherosclerosis in the City of London', this volume, pp. 151-169. In 1928, Rolleston thought that it was "obviously a frequent event" (op. cit., note 7 above, p.93).

${ }^{116}$ Joel D. Howell, 'Early perceptions of the electrocardiogram: from arrhythmia to infarcation', Bull. Hist. Med., 1984, 58: 83-98. It is hard to discover exactly what Lewis thought about angina in the second decade of this century. I think he regarded it of negligible importance when compared to rate and rhythm changes.

The greater part of the myocardium may be termed silent, in precisely the same sense that certain of the areas of the brain are so termed. Conspicuous lesions of the ventricular wall may be present and give rise to neither sign nor symptom. Large areas of muscle may be degenerate, and the symptoms and signs may be few and obscure. But as there are certain tracts in the central nervous system which, when affected, produce manifest disturbances, so, as recent work has shown us, there are tracts in the heart which display their injuries in a conspicuous manner. (Lewis, (1913) op. cit., note 75 above.)

Lewis was addressing himself here to rheumatic affections, but as a general pronouncement it is revealing. Similarly, 'An address on the pathology of heart function', Lancet, 1914, ii: 883, did not mention angina. 


\section{Lawrence}

than a polygraph can do. Mackenzie and Lewis clearly perceived the ECG as a refined polygraph, as did others in the new cardiological community. At the National Heart Hospital, Robert Marshall remembered using the ink polygraph, but said he turned "with relief to the electrocardiograph, which was easier to use and we thought, easier to interpret". ${ }^{117}$ One device substituted for the other: "we had not got an electrocardiograph but used the polygraph", recalled Harold Cookson. ${ }^{118}$ It should be clear, then, why Lewis and others should have used the ECG in this way and why British physicians did not describe myocardial infarction. They had trained themselves to see precise functional relationships between the muscular chambers, but when it came to signals that the heart was failing, they were interested in the performance of the whole myocardium, not in any anatomically distinct part of it. Infarction, like a damaged valve, was not of importance of itself. Herrick, on the other hand, was not educated in this outlook. He used the ECG as a transducer. He was not only interested in the rhythm of the heart but, through the shape of the QRS complex, in its anatomical, not simply its functional, architecture.

\section{INSTITUTIONAL CHANGE AND SPECIALIST APPOINTMENTS}

The new cardiology had been created within a context of changing attitudes to specialization and technology. By 1900, 128 special hospitals had been founded in England and Wales. The governors of general hospitals established special departments, and the Royal College of Physicians frowned less often on Fellows ad Members who pursued a special interest within general medicine. The consultation system was slowly formed and used to foster specialist referrals. Doctors were increasingly educated to use the new instruments and laboratory tests, which were promoted in the medical market place at the turn of the century. The College of Physicians, however, retained its grip. Members and Fellows were to be physicians first and specialists after. ${ }^{119}$ However, even before the work of Mackenzie had become generally known, a particular interest in heart disease was becoming respectable. The status of physicians at the National Heart Hospital rose considerably, of the eleven physicians appointed between 1902 and 1930 only two were not Fellows of the College. One of these was Augustus Waller, a Fellow of the Royal Society and a well-known physiologist. Robert Moon, appointed in 1902, wrote a book on heart disease. ${ }^{120}$ Frederick Price, appointed in 1914, had been an associate of Mackenzie and Cushny. Besides writing one of the most successful textbooks of medicine, Price's first book, published in 1918, was Diseases of the heart. It devoted eleven of its twenty-seven chapters to the ECG, the polygraph, and irregularities of rate and rhythm. Price's preface paid particular homage to Mackenzie but also to Cushny, Lewis, Ritchie, and Hay, amongst others. ${ }^{121}$ Price and

${ }^{117}$ Marshall, op. cit., note 36 above.

118 Cookson, op. cit., note 40 above.

${ }^{119}$ Stevens, op. cit., note 27 above, pp. 26-52.

${ }^{120}$ Robert Moon, The prognosis and treatment of diseases of the heart, London, Longmans Green, 1912. Moon also wrote a historical survey, Growth of our knowledge of heart disease, London, Longmans Green, 1917.

${ }^{121}$ Frederick W. Price, Diseases of the heart, London, Henry Frowde, 1918. The copy in the Wellcome Institute Library belonged to Sir James Mackenzie, and is inscribed "with the gratitude of the author". 


\section{The "new cardiology" in Britain 1880-1930}

Strickland Goodall, also appointed to the hospital in 1914, were, it was said, the first physicians to confine their private consulting practices solely to cardiac cases. ${ }^{122}$ It was not only the staff that changed. In 1911, whilst the hospital was still at Soho Square, an ECG machine was acquired. But the problem of its size meant it had to be installed at South Kensington and the patients transported to it in taxis. In 1914, however, a purpose-built hospital was opened in Westmoreland Street, which is still in use. Appointments to the hospital seem to have been much sought after. When Robert Marshall applied for the job of resident medical officer in 1913, it paid $£ 80$ per annum $-£ 60$ a year more than he was getting in Belfast. ${ }^{123}$ In 1919, postgraduate courses were offered at the hospital.

It was not only at the National Heart Hospital that the study of the heart was institutionalized. At University College Hospital in 1911, Lewis was appointed lecturer in cardiac pathology, a significant title even if it was only a personal one. In the same year, a cardiographic department was established in the basement of the hospital with Lewis in charge. ${ }^{124}$ In 1919 , this department became the first clinical research unit funded by the Medical Research Committee. This was, in a way, official medical recognition of a special interest. In 1911, James Mackenzie was appointed lecturer in cardiac research at the London Hospital Medical College. But it was not until 1913, and in the face of senior staff opposition, that Mackenzie was appointed a consultant at the London Hospital itself. A cardiac department was established, and John Parkinson employed as first assistant. But provincial practitioners, however distinguished, had no passport to the élitism of the capital. Of Mackenzie's days at the London, Thomas Cotton remarked: "At the London his colleagues ... did not think highly of him". ${ }^{125}$ In 1913, St Bartholomew's Hospital acquired its first ECG machine. The moving influence there was John Hannah Drysdale, an assistant physician who purchased the machine himself. Geoffrey Bourne remembered: "Only a small minority of the physicians had at that time, any idea of the clinical value of electrocardiography. Drysdale, Langdon Brown and Horder alone knew what auricular fibrillation was." ${ }^{126}$ Significantly too, Langdon Brown was a forceful exponent of the relevance of experimental physiology and other new disciplines to clinical medicine. He took up endocrinology, was one of the earliest English disciples of Freud, and eventually became Regius Professor of Physic at Cambridge. Thomas Horder, of course, was one of the most renowned physicians of the day. There is thus plenty of evidence that during the second decade of the century the ECG was being used, or the new cardiology pursued or departments formed where able and ambitious clinicians grasped the intellectual changes and, on their own initiative, set about institutionalizing them.

The other way in which clinicians pursuing a special interest could advertise their identity was by the publication of a journal. The neurologists had Brain, which had

\footnotetext{
${ }^{122}$ Munk's Roll, vol. 5, op. cit., note 25 above, p.338. Campbell hints that such specialist practice flourished and was lucrative.

${ }^{123}$ Marshall, op. cit., note 36 above.

124 W.R. Merrington, University College Hospital and its Medical School: a history, London, Heinemann, 1976, pp.192-196.

${ }^{125}$ Quoted in Mair, op. cit., note 50 above, p.265.

${ }^{128}$ Bourne, op. cit., note 38 above.
} 


\section{Lawrence}

been published continuously since 1878. In 1909, Thomas Lewis "with Mackenzie's support" launched the journal, Heart. ${ }^{127}$ Coincidentally, perhaps, the French journal Archives des Maladies du Coeur et des Vaisseaux had appeared a year earlier. Heart was edited by Lewis, assisted in the selection of papers by Gaskell, Cushny, Leonard Hill, and Mackenzie. With two physiologists, an experimental pharmacologist, and two clinicians, this was clearly no ordinary journal of bedside medicine.

From the start, the journal followed Lewis's interests, the papers being devoted primarily to investigations associated with the electrical properties of the heart. Lewis was author or part-author of one-quarter of the articles published during the journal's twenty-four years of life. Significantly, in the 1920s, when Lewis's interest began to move away from the heart towards the circulation generally and then later into the question of pain, so the contributions to the journal followed the same pattern. In 1933, with Lewis still editor, it was renamed Clinical Science and scarcely contained any cardiological contributions. Lewis's distinguished assistants on the editorial board, T.R. Elliott, R.T. Grant, P.P. Laidlaw, Edward Mellanby, Wilfred Trotter, and E.B. Verney, were accomplished research workers but scarcely cardiologists. This shift in direction by Lewis must have made the 1930s a curious period for British clinical cardiologists with no obvious journal to circulate amongst them. It is not surprising, then, that eventually a new journal, the British Heart Journal, was established, appearing first in 1939.

\section{THE WARTIME EXPERIENCE}

Cardiology as an institutionalized medical speciality did not exist in Britain until after the Second World War. Sir Ian Hill remembered: "in the 1930s a cardiologist was usually a general physician with a special interest in cardiovascular disease". ${ }^{128}$ Even as late as 1943, Lewis had apparently written to Herrick complaining about the "ugliness" of the word. ${ }^{129}$ However, in spite of no obvious career structure in cardiology, by the end of the second decade of this century, a small number of men were actively pursuing the new subject on as near a full-time basis as was possible. A crucial crystallizing factor in this development seems to have been the First World War, and the problem of "soldier's heart", which was both formulated and resolved within the new cardiological framework. ${ }^{130}$

Run-of-the-mill military doctors who examined recruits or repatriated men from the front were not the new cardiologists, and, as mentioned, had only two diagnoses, $\mathrm{VDH}$ and DAH. There were a large number of these cases for, after wounds, injuries, and chest complaints, "Heart Disease" formed the largest group of pensioned men discharged from the army. By 1918 , there were 36,569 in all. ${ }^{131}$

\footnotetext{
${ }^{127}$ Hollman, op. cit., note 66 above, p.55.

${ }^{128}$ Hill, op. cit., note 39 above, p.55.

${ }^{129}$ Wellcome Institute, Contemporary Medical Archives Centre, PP/LEW J1/85, Herrick to Lewis, Chicago, 1 February 1943. Lewis's idiosyncrasy should be borne in mind here.

${ }^{130}$ For a detailed analysis see Howell, op. cit., note 66 above.

${ }^{131}$ I confess I am unable to recover my source for these remarkably precise figures. But on the importance of heart disease in World War I see Howell, ibid.
} 


\section{The "new cardiology" in Britain 1880-1930}

In 1909, Mackenzie had been appointed to the staff of the Mount Vernon Hospital for Chest Diseases at Hampstead. This hospital was vacated in 1913, and acquired by the newly instituted Medical Research Committee. In 1914, however, it was handed over to the War Office to become the Hampstead Military Hospital. In 1915, Mackenzie wrote to Parkinson at the front that, in view of the number of cases of soldier's heart being invalided home, he had submitted a memorandum to Allbutt and Osler suggesting that a special hospital should be set up devoted to studying this condition. ${ }^{132}$ The result was that 400 beds at Hampstead were set aside for the study of soldier's heart. Mackenzie, Allbutt, and Osler were to act in a consulting role; Lewis, now Captain Lewis, was to work there full time as a member of the staff of the Research Committee. In autumn 1917, still under Lewis, the hospital transferred to Colchester.

In one way or another, several of the men who were to lead and give shape to British cardiology in the 1920s were associated with this wartime experience. John Parkinson, formerly chief assistant to James Mackenzie, and in 1914 medical officer at casualty clearing stations in France, became, in 1916, divisional officer at Hampstead. Between 1916 and 1918, Parkinson published several papers on soldier's heart and disorders of the heart rate and rhythm. ${ }^{133}$ Thomas Cotton, a Canadian, worked with Lewis in 1913, and after a brief spell in Canada, returned to work at Hampstead and then Colchester. Cotton had published on ventricular hypertrophy in Heart in $1916 .{ }^{134}$

What is significant in all this is that the War Office had given official recognition to special categories of disease and in turn appointed men with special abilities to deal with the problems. Likewise, at the National Heart Hospital in 1916, the War Office had asked the staff to assess recruits with doubtful heart conditions. Within two years, 10,000 men had been examined and the results written up by the consulting staff. ${ }^{135}$ The eventual outcome of all this wartime work was that contemporaries accepted that the researchers had demolished the old DAH, VDH categories. Lewis and his group, and others, showed that patients in both groups had valvular deformations, and were able to distinguish patients in both classses in which severe cardiac symptoms appeared without any associated structural abnormalities. This condition was labelled "Effort Syndrome" by Lewis, and he believed it to be caused by various factors, notably some prior infection. It was a functional cardiac disorder in the new sense.

The war had brought to the fore a number of able clinicians, practitioners of the new cardiology who were able to find employment for their cardiological expertise in the post-war world. The aftermath of war had left a mass of sick and wounded, many eligible for pensions. In 1920, the government appointed consultants to assist the

\footnotetext{
${ }^{132}$ Mair, op. cit., note 50 above, p.236.

${ }^{133}$ Parkinson perhaps stood for the opposite of everything the older generations of clinicians approved of. He ridiculed the mystique surrounding clinical techniques such as percussion of the heart: he applauded technological investigation, and "fought for the recognition of cardiology as a speciality" [Obituary], Lancet, 1976, i: 1359.

${ }^{134}$ On Cotton, see D. Evan Bedford, 'Thomas Forrest Cotton', Br. Heart J., 1966, 28: 137. Bedford records that whilst working with Lewis, Cotton had a private practice as a "consultant cardiologist".

${ }^{135} \mathrm{~S}$. R. Wells, 'Ten thousand recruits with doubtful heart conditions', Br. med. J., 1918, i: 556-559; ii: 248-251.
} 


\section{Lawrence}

regional directors of the Pension Service in the assessment of cases. A number of these consultants were appointed for their cardiac skills. It is interesting to see in these appointments the network of relationships that tied some of the consultants into the Mackenzie-Lewis network and the practice of the new cardiology.

Thomas Cotton, John Hay, and John Parkinson, as well as Lewis himself, were appointed. In addition, there was a post for Kenneth Wilkinson, who worked for about a year with Lewis in the post-war period. ${ }^{136}$ Wilkinson was a close friend of Parkinson and Horder, who had also been appointed. There was also Wardrop Griffith, by this time sixty years old, a physician at Leeds and a lifelong friend of Mackenzie's, and an experienced user of the polygraph. The other appointments were men who had already demonstrated their interest in the new cardiology, Joseph Emanuel, John Cowan, William Ritchie, and William Hume. These, with the pathologist A.G. Gibson and Carey Coombs, were the fifteen Ministry consultants who at a meeting in 1922 founded the Cardiac Club. ${ }^{137}$

The formation of the Cardiac Club can be taken as an important point in the history of British cardiology conceived of as an institutionalized discipline devoted to a special object of study. Its membership comprised a number of well-established physicians committed to a particular outlook in clinical medicine. Over the next few years, the club was to recruit others who had achieved or would achieve influential posts within British medicine and who endorsed the importance of basic science and the use of technology, and who were committed to a limited form of specialist practice. By the 1920 s, cardiology was a perfectly reputable speciality for a physician to follow in his consulting rooms. Likewise, there existed a few specialized junior hospital job opportunities in various hospital cardiac departments. There was a journal, a club, a recognized leadership, a technology, and most, important of all, a coherent intellectual discipline.

The perspective of the new cardiology was not to last in its entirety, no more than had the pathological anatomy of its forerunner. The description of myocardial infarction was to reintroduce the local pathological disease entity; the theory of back pressure was to reappear in new form after the application of Starling's work by clinicians a decade later. ${ }^{138}$ As chest surgeons began to flex their youthful muscles,

\footnotetext{
${ }^{136}$ See C.G. Parsons, 'K.D. Wilkinson', Br. Heart J., 1951, 13: 556-568.

${ }^{137}$ In 1927, a university centre of cardiac research was established at Bristol, with Carey Coombs as its director. [Obituary], Br. med. J., 1932, ii: 1126.

${ }^{138}$ For an interesting account of the use of Starling's theory to refute the forward pressure hypothesis in the 1930s, see Sir George Pickering, 'Starling and the concept of "heart failure", Circulation, 1960, 21: 323-331. As I understand Pickering, he suggests that Lewis thought that "the height of the venous pressure was the best guide to the presence and severity of heart failure" yet regarded this in some way as stemming from output failure. See also Basil Thomas Parsons-Smith, 'Cardiac failure', Lancet, 1950, i: 889-894, 943-947. One can possibly detect in Rolleston's account of 1928 the signs of retreat from the "functionalism" of the new cardiology.

During the later half of the last century an exaggerated importance was attached to cardiac, and especially systolic, murmurs as evidence of heart disease. With the passing of morbid anatomy, or the overshadowing of gross morbid changes by the renewed attention to symptoms and physiological efficiency, there has now resulted a diminution in the importance attached to the physical signs of cardiac disease. But the traditional stress laid on the presence or absence of a murmur as the criteria in determining whether the heart was or was not affected, though qualified by the wise warnings of W.T. Gairdner (1862), Thomas Watson, Andrew Clark, G.W. Balfour, and others, did not become fully discounted until after the War, and then largely by Mackenzie's
} 


\section{The "new cardiology" in Britain 1880-1930}

they challenged the conceptions of the new cardiology because, of course, they regarded the gross lesion as crucial. ${ }^{139}$ Similarly, paediatricians began emphasizing the importance of the congenital defect. ${ }^{140}$ Blood pressure, too, was given new significance in the 1930s. For all that, a new intellectual structure had been built by the 1920s, which could incorporate these things. Meanings would be changed again but never so profoundly. The arguments about the relation between the basic sciences and clinical medicine continued into the 1920 s as the writings of Lewis attest. But, in a way, experimental physiology had been incorporated into clinical medicine almost so effectively as to be taken for granted and hardly perceived specifically as physiology at all. There had come into existence a generation of men dedicated to a special area of investigation, prepared to use instruments, and, most importantly, in terms of the rise of basic science, thinking about the heart's unique living properties. If the particular experiments of the laboratory seemed far away, the ethos of the bench was omnipresent. New intellectual configurations and institutional changes did come. But the subject and its sites of practice did not have to be fundamentally reshaped to accommodate them.

\section{ACKNOWLEDGEMENTS}

For reading and commenting on this paper at various stages I should like to thank David Armstrong, W.F. Bynum, Gerald L. Geison, Joel Howell, Jonathan Liebenau, Sir William Paton, Roy Porter, Ghislaine Skinner, and John Harley Warner.

insistence. Indeed in 1914 medical officers recommeded that soldiers with a systolic murmur should be discharged from the service. The great stress laid on diagnosis obscured the importance of prognosis, for which knowledge of the condition of efficiency of the myocardium is essential; but with the swing of the pendulum the myocardial factor is now well recognized in the principle that the diagnosis of valvular disease is determined by the auscultatory detection of murmurs, whereas its prognosis depends on the estimation of myocardial efficiency. (Rolleston, op. cit., note 7 above, p.81.)

${ }^{139}$ Mackenzie, Lewis, and Carey Coombs all argued against valve sugery on the grounds that it did not treat what was basically wrong, the functioning of the heart muscle. Maurice Campbell remembered: "Modern cardiology was only just starting and two of its principles were not helpful to the operation. These were that the state of the heart muscle was of overriding importance: and that mitral regurgitation was much less common than had been thought." Souttar's operations for mitral stenosis struck Campbell as much less interesting than new pharmacological approaches. See Maurice Campbell, 'The early operations for mitral stenosis', Br. Heart J., 1965, 27: 670-673. Souttar, on the other hand, thought "the problem is to a large extent mechanical". H.S. Souttar, 'The surgical treatment of mitral stenosis', Br. med. J., 1925, ii: 603-606. For an account of Mackenzie's incredulousness at the thought of valve surgery, see McMichael, op. cit., note 59 above. The denial of the importance of the lesion led the cardiac surgeon, Russell Brock, to declare: "I can only conclude it is something in the very nature or atmosphere of the Royal College of Physicians-perhaps a cloud of some special canonizing dust falls upon its habitués" (Arthur Hollman, personal communication). John Harley Warner has suggested to me that had I considered therapeutics and not diagnosis I might have been able to make a similar argument. "I wonder if it would not be possible to talk about a change in the way clinicians conceived of the desired end-point of therapeutic activity, that is what it meant for the 'living heart' to be a healthy/normal heart and what criteria would be used to judge both what needed to be normalized and the effected normalization."(Personal communication.)

${ }^{140}$ See Forrest H. Adams, 'Development of paediatric cardiology', Amer. J. Cardiology, 1968, 22: 452-455. Campbell remembered that after the formation of the Cardiac Club, "only once in 15 years ... did congenital heart disease have more than a passing mention" (op. cit., note 6 above, p.681). 